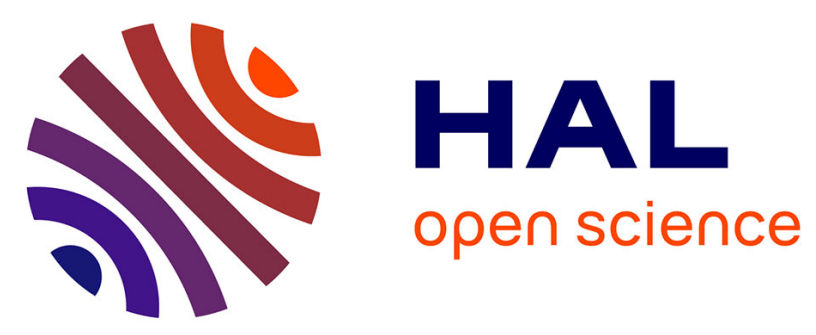

\title{
Understanding biogeobatteries: Where geophysics meets microbiology
}

\author{
A. Revil, C. A. Mendonça, E. A. Atekwana, B. Kulessa, S. S. Hubbard, K. J. \\ Bohlen
}

\section{- To cite this version:}

A. Revil, C. A. Mendonça, E. A. Atekwana, B. Kulessa, S. S. Hubbard, et al.. Understanding biogeobatteries: Where geophysics meets microbiology. Journal of Geophysical Research: Biogeosciences, 2010, 115, pp.G00G02. 10.1029/2009JG001065 . insu-00565367

\section{HAL Id: insu-00565367 https://hal-insu.archives-ouvertes.fr/insu-00565367}

Submitted on 11 Mar 2021

HAL is a multi-disciplinary open access archive for the deposit and dissemination of scientific research documents, whether they are published or not. The documents may come from teaching and research institutions in France or abroad, or from public or private research centers.
L'archive ouverte pluridisciplinaire HAL, est destinée au dépôt et à la diffusion de documents scientifiques de niveau recherche, publiés ou non, émanant des établissements d'enseignement et de recherche français ou étrangers, des laboratoires publics ou privés. 


\title{
Understanding biogeobatteries: Where geophysics meets microbiology
}

\author{
A. Revil, ${ }^{1,2}$ C. A. Mendonça, ${ }^{3}$ E. A. Atekwana, ${ }^{4}$ B. Kulessa, ${ }^{5}$ S. S. Hubbard, ${ }^{6}$ \\ and K. J. Bohlen ${ }^{1}$ \\ Received 2 June 2009; revised 2 September 2009; accepted 22 September 2009; published 17 February 2010.
}

[1] Although recent research suggests that contaminant plumes behave as geobatteries that produce an electrical current in the ground, no associated model exists that honors both geophysical and biogeochemical constraints. Here, we develop such a model to explain the two main electrochemical contributions to self-potential signals in contaminated areas. Both contributions are associated with the gradient of the activity of two types of charge carriers, ions and electrons. In the case of electrons, bacteria act as catalysts for reducing the activation energy needed to exchange the electrons between electron donors and electron acceptors. Possible mechanisms that facilitate electron migration include iron oxides, clays, and conductive biological materials, such as bacterial conductive pili or other conductive extracellular polymeric substances. Because we explicitly consider the role of biotic processes in the geobattery model, we coined the term "biogeobattery." After theoretical development of the biogeobattery model, we compare model predictions with self-potential responses associated with laboratory and field scale investigations conducted in contaminated environments. We demonstrate that the amplitude and polarity of large $(>100 \mathrm{mV})$ self-potential signatures requires the presence of an electronic conductor to serve as a bridge between electron donors and acceptors.

Small self-potential anomalies imply that electron donors and electron acceptors are not directly interconnected, but instead result simply from the gradient of the activity of the ionic species that are present in the system.

Citation: Revil, A., C. A. Mendonça, E. A. Atekwana, B. Kulessa, S. S. Hubbard, and K. J. Bohlen (2010), Understanding biogeobatteries: Where geophysics meets microbiology, J. Geophys. Res., 115, G00G02, doi:10.1029/2009JG001065.

\section{Introduction}

[2] Recent investigations both in the field [Naudet et al., 2003, 2004; Minsley et al., 2007] and in the laboratory [Naudet and Revil, 2005] show that organic-rich contaminant plumes behave as geobatteries that produce an electrical source current in the electrically conductive ground [Arora et al., 2007; Linde and Revil, 2007]. The manifestation of this current can be observed by measuring the electrical potential distribution at the ground surface of the Earth with nonpolarizing electrodes, a method known in geophysics as the self-potential method [Sato and Mooney, 1960; Corwin, 1997]. While the abiotic process of geobatteries associated with ore deposits has been well documented in exploration

\footnotetext{
${ }^{1}$ Department of Geophysics, Colorado School of Mines, Golden, Colorado, USA.

${ }^{2}$ LGIT, UMR 5559, Equipe Volcan, University of Savoie, CNRS, Le Bourget-du-Lac, France.

${ }^{3}$ Geofísica e Ciências Atmosféricas, Instituto de Astronomia, Sao Paulo, Brazil.

${ }^{4}$ Boone Pickens School of Geology, Oklahoma State University, Stillwater, Oklahoma, USA.

${ }^{5}$ School of the Environment and Society, Swansea University, Swansea, UK.

${ }^{6}$ Earth Science Division, Lawrence Berkeley National Laboratory, Berkeley, California, USA.
}

Copyright 2010 by the American Geophysical Union. 0148-0227/10/2009JG001065\$09.00 geophysics [Sivenas and Beales, 1982; Stoll et al., 1995], the mechanistic, possibly biotic, process of the geobattery associated with contaminant plumes remains a subject of much debate.

[3] The term "biogeobattery" is coined to suggest the role of biotic processes in the generation of electrical currents in the conductive ground. We explore below the mechanisms leading to the formation of geobatteries, their associated self-potential response, and the potential active or passive role of bacteria in these systems. Understanding the concept of biogeobatteries requires bridging geophysical, geochemical, and microbiological models and methods. We limit our geophysical discussions to the study of selfpotential signals over contaminant plumes and demonstrate why the amplitude and polarity of self-potential signals recorded at the ground surface requires an electronic conductor to bridge electron donors and acceptors. We show that the absence of strong $(>100 \mathrm{mV}$ ) self-potential anomalies seems to be in turn related to the absence of an electron conductor. In this case, the self-potential anomalies are explained as diffusion potentials resulting from gradients of the chemical potential of the ions [Revil et al., 2009].

[4] We honor below both geophysical, geochemical, and microbiological concepts to develop and test a biogeobattery model that links the electrical potential distribution measured passively at the ground surface of the Earth to the in situ distribution of the redox potential and electrochem- 


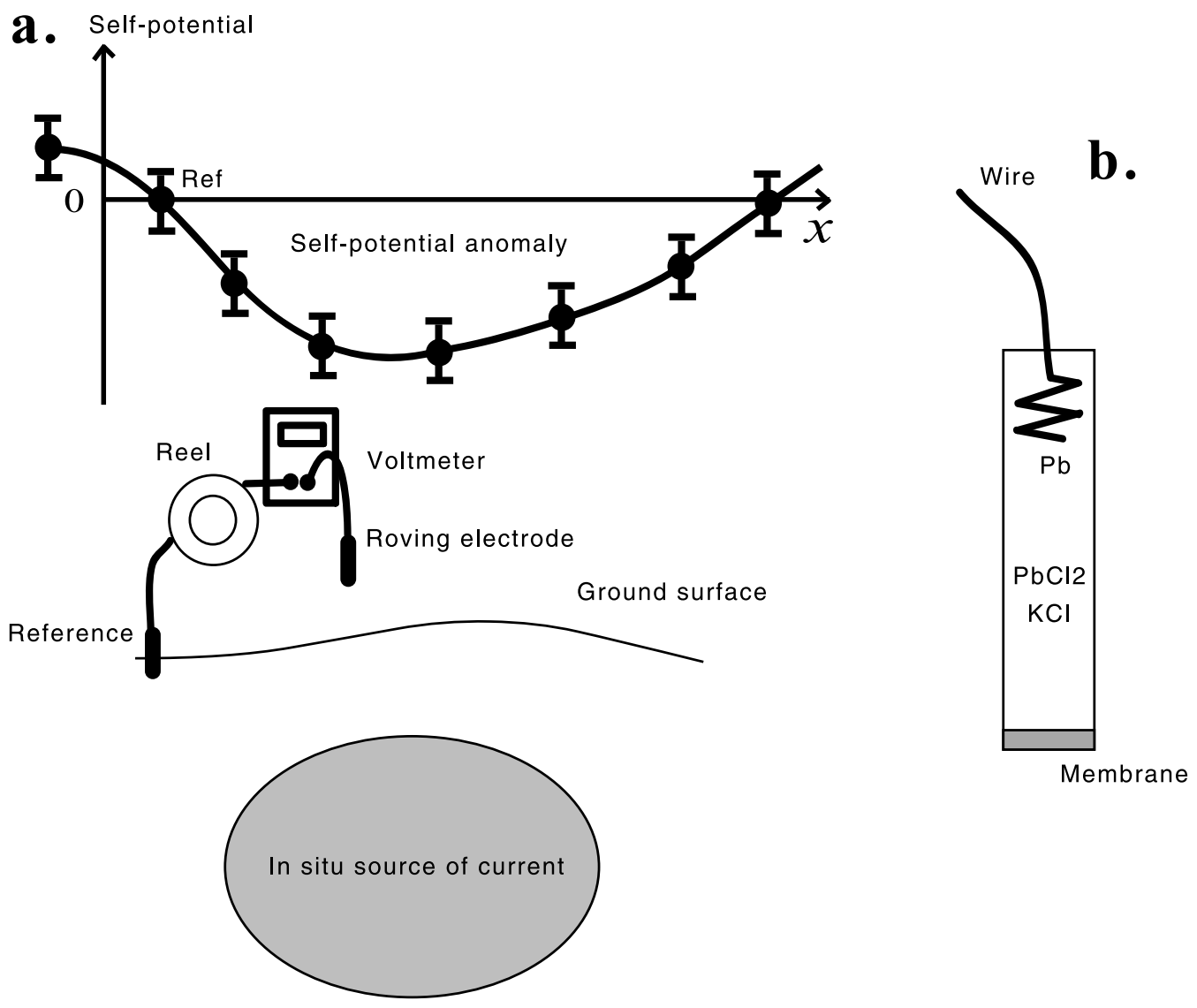

Figure 1. Principle of the self-potential method. (a) The self-potential is the passive measurement of the electrical potential at the ground surface using a voltmeter. The measured potential is relative to the unknown potential at the position of a fixed electrode called the reference base station. The roving electrode is used to scan the value of the electrical potential to a set of self-potential stations. Each selfpotential station corresponds to a small hole in which the contact between the roving electrode and the ground can be improved by adding bentonite, a smectite-rich clay. From the measurements at each base station, we define a mean and a standard deviation. A self-potential anomaly indicates the presence of a current density at depth. (b) Sketch of a nonpolarizing electrode (a metal in its salt). The end-contact of the electrode with the ground is made through a membrane (ceramic or wood).

istry. Our paper is organized as follows. Section 2 provides a short background regarding the self-potential method. Section 3 describes the abiotic geobattery concept used to describe self potential signals associated with ore bodies. Section 4 discusses the development of the biogeobattery model, which relies on subsurface microbes to serve as catalysts for electron transport between electron donors and acceptors and the potential role of conductive pili in this process. We test some aspects of the developed theory using self-potential data sets collected at both the laboratory and field scales in section 5, and confirm that the theoretical and experimental results are in agreement. Section 6 discusses some potential mechanisms associated with the nature of the electron transfer in environmental systems, which raises interesting questions for future research.

\section{Self-Potential Method}

[5] The self-potential method is a passive electrical method in geophysics that consists of measuring passively the electrical potential distribution at the ground surface of the Earth (possibly in boreholes) with respect to a fixed electrode located somewhere in the field. This fixed electrode is termed the reference electrode. The position of the reference electrode is termed the base station. A typical selfpotential survey is sketched in Figure 1a. The self-potential measurements are usually performed with two nonpolarizing electrodes (e.g., $\mathrm{Cu} / \mathrm{CuSO}_{4}$ or $\mathrm{Pb} / \mathrm{PbCl}_{2}$, Figure 1b) and a sensitive high-input impedance voltmeter (sensitivity $\sim 0.1 \mathrm{mV}$, input impedance $>10 \mathrm{Mohm}$ ). A description of the method is given by Corwin [1997] for instance. Because the self-potential data are collected with respect to the potential of the reference electrode (which is unknown), a self-potential field is defined to an arbitrary constant. Only the electrical field, defined as the tangential gradient of the self-potential with respect to the coordinates describing the topography of the ground surface, is meaningful.

[6] The existence of self-potential anomalies implies the presence of a source of electrical current in the ground [Sill, 1983; Minsley et al., 2007]. In isothermal conditions, there are three contributions to the in situ current density. The first contribution is associated with the flow of the groundwater [Rizzo et al., 2004] and is called the streaming potential contribution. The second and third contributions are asso- 
ciated with the gradient of the chemical potential of charge carriers. Two types of charge carriers are electrons [Sato and Mooney, 1960] and ions [Revil and Linde, 2006]. Although these contributions are recognized, there is no model to date to link the self-potential response with biotic processes associated with some contaminant plumes.

\section{Ideal Linear Geobattery Model}

[7] In this section, we describe the components that are used in section 4 to develop the biogeobattery model, including the redox potential, the geobattery concept, and the dipolar nature of the self-potential field.

\subsection{Redox Potential}

[8] The relative electron activity of water is defined as $p \varepsilon=-\log \left\{\mathrm{e}^{-}\right\}$where $\left\{\mathrm{e}^{-}\right\}$represents the potential electron activity in the pore water phase [Holstetler, 1984; Thorstenson, 1984]. In a reducing system, the tendency to donate electrons, or electron activity, is relatively large and $p \varepsilon$ is low. The opposite holds true in oxidizing systems. In a reduction reaction, an oxidized species $\mathrm{Ox}$ reacts with $n$ electrons to form a reduced species Red. The half-reaction $\mathrm{Ox}+n e^{-} \rightarrow$ Red is characterized by a reaction constant $K=\{\operatorname{Red}\} /\{\mathrm{Ox}\}\left\{\mathrm{e}^{-}\right\}^{n}$. Because there is no electron in the pore water, the previous reduction reaction has to be coupled with an oxidation reaction (typically for reference purpose the oxidation of hydrogen). This leads to,

$$
p \varepsilon=p \varepsilon^{0}+\frac{1}{n} \log \left(\frac{\{\mathrm{Ox}\}}{\{\operatorname{Red}\}}\right)
$$

where $p \varepsilon^{0}$ the standard electron activity of the actual reduction half-reaction when coupled to the oxidation of hydrogen under standard conditions [Christensen et al., 2000]. The redox potential is defined through the Nernst equation by,

$$
E_{H}=2.3 \frac{k_{b} T}{e} p \varepsilon
$$

where $T$ is the absolute temperature in $\mathrm{K}, e$ is the elementary charge of the electron, and $k_{b}$ is the Boltzmann constant. Usually, the measurement of the redox potential is performed with platinum electrodes in equilibrium with the $\mathrm{Fe}(\mathrm{II}, \mathrm{III})$ redox couple with a possible contamination by the $\mathrm{O}_{2} / \mathrm{H}_{2} \mathrm{O}$ redox couple at low concentration in iron (below $10^{-5} \mathrm{M}$ ) [Nordstrom, 2000]. Equilibrium implies that one can use the Nernst equation to determine the value of the redox potential. No other redox couples (with the exception of $U(I V, V I)$ in natural aquatic systems) are known to produce an equilibrium potential at an electrode surface [Nordstrom, 2000]. The concept of the redox potential should be therefore defined in terms of redox couples and reactions.

\subsection{A Linear Idealized Geobattery Model}

[9] Various geobattery models have been published in the geophysical literature since the seminal work by Sato and Mooney [1960]. Sato and Mooney [1960] developed a model to explain the self-potential signals associated with massive ore bodies in the context of exploration geophysics. Bigalke and Grabner [1997] later proposed a nonlinear model based on the Butler-Volmer equation, a classical nonlinear equation between the current and the voltage used to describe the source current density at the surface of metallic electrodes. This approach was recently applied by Mendonça [2008] for developing an inversion algorithm to retrieve the source of current associated with ore bodies. The reason for the nonlinearity in the geobattery model of Bigalke and Grabner [1997] is that the exchange of electrons to and from metallic bodies requires certain activation energies, which translate into potential losses [Bockris et al., 1970]. The larger the current flowing from the surrounding ground, the larger these potential losses, and the larger the nonlinear behavior of the geobattery.

[10] We consider a massive ore body embedded in the conductive ground as shown in Figure 2a. Electrons within the ore body have a high mobility but do not exist in the surrounding rock mass. The presence of the ions controls the electrical conductivity in the surrounding rock mass. Because the fugacity of oxygen (the concentration of $\mathrm{O}_{2}$ dissolved in water) decreases with depth, the redox potential has, in the far field of the ore body, a strong dependence with the depth $z$. In the vicinity of the ore body, the distribution of the redox potential can be more complex because of contribution of interfacial processes and possibly biological activity [Kelley et al., 2006]. Castermant et al. [2008] performed a laboratory experiment using a corroding iron bar in a sandbox. This experiment serves as an analog for a buried ore. They noticed a difference between the far field and the near-field distributions of the redox potential in the vicinity of a corroding iron bar. The near-field distribution of the redox potential was influenced by anodic and cathodic reaction.

[11] Let us consider for example the corrosion of an ore body like pyrite $\mathrm{FeS}_{2}$. Reactions $\mathrm{S}(-\mathrm{II})$ and $\mathrm{S}(0)$ in pyrite coupled to release of $\mathrm{SO}_{4}^{2-}$ and $\mathrm{Fe}^{2+}$ at depth, coupled to (2) the reduction of oxygen near the oxic/anoxic interface (typically the water table). The soluble Fe released during the anodic reaction at depth can then eventually react, through advective, dispersive, and electromigration transport, with oxygen at the water table. It is therefore responsible for the distribution of the redox potential in the vicinity of the ore body. This mechanism can be summarized by the following reactions. At depth at the surface of the ore body, the following half-reaction occurs,

$$
\mathrm{FeS}_{2}+8 \mathrm{H}_{2} \mathrm{O}=\mathrm{Fe}^{2+}+2 \mathrm{SO}_{4}^{2-}+14 \mathrm{e}^{-}+16 \mathrm{H}^{+}
$$

which is an abiotic half-reaction pulled along by sinks for electrons and $\mathrm{Fe}^{2+}$ at the oxic/anoxic interface. At the cathode, possibly in the vadose zone (Figure 2), we can have the following reactions,

$$
14 \mathrm{e}^{-}+3.5 \mathrm{O}_{2}+14 \mathrm{H}^{+}=7 \mathrm{H}_{2} \mathrm{O}
$$

$$
\begin{aligned}
& 4 \mathrm{Fe}^{2+}+\mathrm{O}_{2}+4 \mathrm{H}^{+}=4 \mathrm{Fe}^{3+}+2 \mathrm{H}_{2} \mathrm{O} \\
& 4 \mathrm{Fe}^{3+}+12 \mathrm{H}_{2} \mathrm{O}=4 \mathrm{Fe}(\mathrm{OH})_{3}+12 \mathrm{H}^{+} .
\end{aligned}
$$



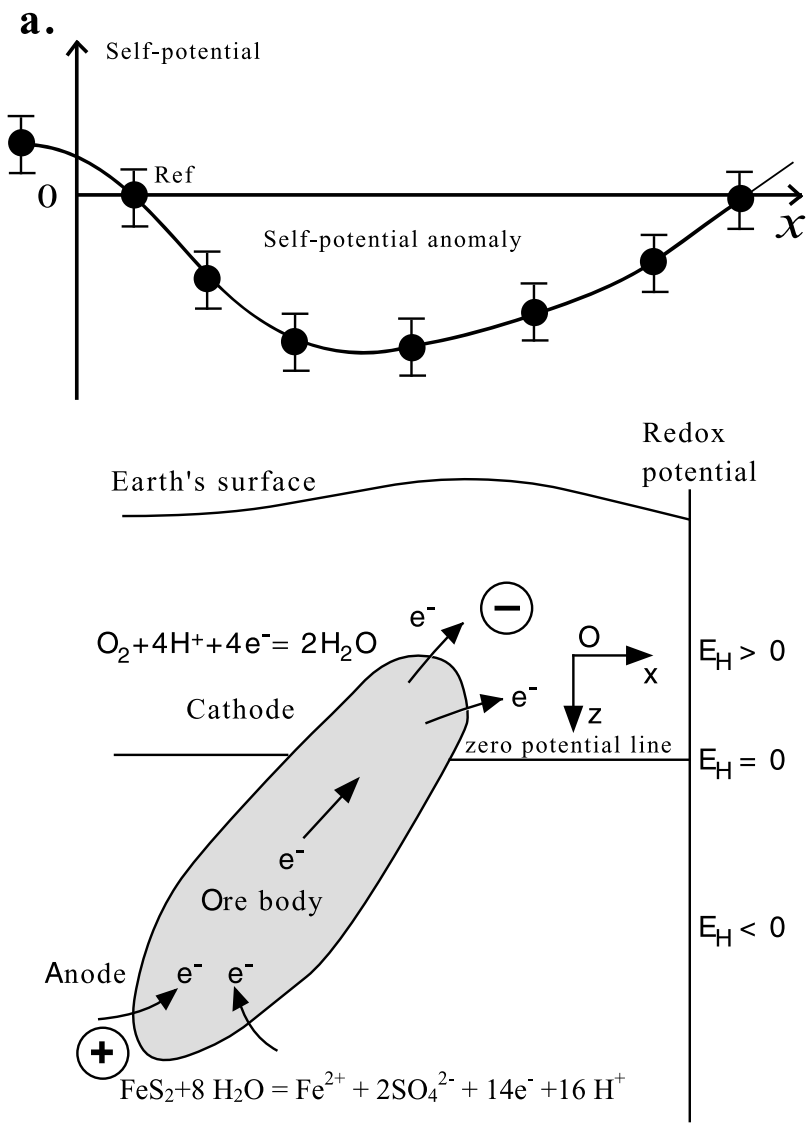

b. Equivalent circuit

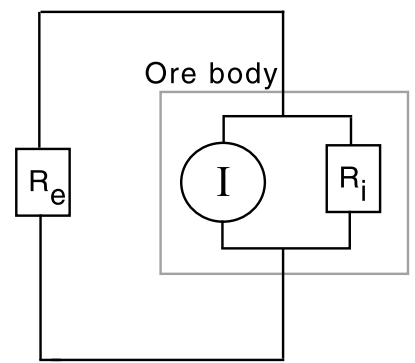

Figure 2. Sketch of the classical geobattery model proposed for ore bodies and equivalent linear circuit. (a) In the far field, the redox potential decreases with depth. In the vicinity of the ore body a disturbance of this far field is created because of the redox reactions at the surface of the ore body. Corrosion of the ore body can also be responsible for a resistive crust that adds an additional Ohmic resistance (and therefore an overvoltage) to the circuit. Typically, a self-potential anomaly associated with an ore body can amount to a few hundreds of millivolts at the ground surface but cannot be higher than the difference of the redox potential between the terminal points (anode and cathode) of the system. (b) The ore body is characterized by a source of current $I$ and an internal resistance $R_{\mathrm{i}}$. The resistance $R_{\mathrm{e}}$ stands for the external resistance of the conductive medium in which the ore body is embedded.

Reaction (4) corresponds to the half-reaction associated with the electrons provided by the ore body. Reaction (5) is a redox reaction in the solution with the microorganisms being potentially able to accelerate this reaction depending on the $\mathrm{pH}$ of the solution (low $\mathrm{pHs}$ favor the reaction). Reaction (6) is the $\mathrm{Fe}(\mathrm{III})$ oxide mineral precipitation, which is an abiotic reaction. It is important to realize that the vertical redox gradient in the vicinity of the ore body, in addition to being influenced by reactions associated with the corrosion of the ore body (equations (3) - (6)), could be also influenced by redox reactions (possibly microbially catalyzed) that are unrelated to ore body corrosion, e.g., reactions associated with degradation of organic matter in the aquifer sediments surrounding the ore body in the way envisioned below in section 6 . In this case, the ore body would serve as a conductor for transfer of electrons released during these reactions from depth to the oxic/anoxic interface [Bigalke and Grabner, 1997].

[12] The distribution of the redox potential should thus be viewed as a general source mechanism that drives electrical current flow inside the ore body because, from a thermo- dynamic standpoint, a gradient of the chemical potential of charge carriers (here the electrons) corresponds to a driving force for an electrical current density A sketch of the equivalent circuit is shown in Figure 2b. Two models of battery are possible. In one, the ore body serves directly as a source of electrons, vis-à-vis equation (3), that flow from depth to the shallow subsurface through the ore body. Equation (3) describes a source of electrons originating from the oxidation of the ore body. This corresponds to an "active electrode" model. In the second model, called the "passive electrode model," the ore body serves simply as a conductor for transfer of electrons that originate from redox reactions (potentially microbially catalyzed) that take place away from the ore body and have nothing to do with the corrosion of the ore body. Both models can coexist. For example, the 14 electrons released in half-reaction (3) can pass directly through the ore body to oxygen at the aerobic/ anaerobic interface, while the electrons released during the oxidation of $\mathrm{Fe}^{2+}$ in solution at or near the ore body/water interface (as illustrated in Figure 2) can also be transmitted to the shallow subsurface through the ore body. 
[13] In the low-frequency limit of the Maxwell equations, the electric field $\mathbf{E}$ and total current density $\mathbf{j}$ obey:

$$
\begin{gathered}
\nabla \times \mathbf{E}=0, \\
\nabla \cdot \mathbf{j}=0 .
\end{gathered}
$$

Equation (7) implies that the electrical field can be derived directly from an electrostatic potential $\psi$ with $\mathbf{E}=-\nabla \psi$. Equation (8) means that in steady state conduction, the total current density is conservative.

[14] Outside the ore body, the classical Ohm's law holds, and therefore the current density is given by $\mathbf{j}=\sigma \mathbf{E}$, where $\sigma$ is the electrical conductivity of the surrounding material. Inside the ore body, an extra source current density exists. In a linear geobattery model, this source current density is,

$$
\mathbf{j}_{S}=\sigma \mathbf{E}_{e},
$$

where $\mathbf{E}_{e}$ is the thermodynamic force driving the transfer of charges inside the ore body. Outside the ore body, $\mathbf{E}_{e}=0$. This suggests that the electrical circuit under consideration is formed by a generator (the ore body), and an external part (the conductive ground outside the ore body). From the standpoint of potential field theory [Blakely, 1995], the ore body is a source of current and the goal of a geophysical survey is to establish a relationship between the localization (and geometry) of this source of current and the measurements of the resulting self-potential signals in boreholes or at the ground surface of the Earth. In turn, such a forward relationship can be used within inversion frameworks to estimate the characteristics of the source (position, geometry, distribution of the redox potential at its boundaries, operating half-reactions).

[15] The electromotive force is defined as the voltage of the driving force of the source current density between the terminal points of the generator (the cathode in the upper side and the anode in the lower side, see Figure 2a),

$$
E_{\text {emf }}=\int_{(-)}^{(+)} \mathbf{E}_{e} \cdot d \mathbf{l}
$$

where $d \mathbf{l}$ is a length unit vector along a current line, $(+)$ describes the anode, and (-) the cathode (Figure 2). In our case, the thermodynamic force driving the transfer of charges inside the ore body is of chemical origin. This force is the gradient of the chemical potential of the electrons, hence the redox potential. Therefore, we have $\mathbf{E}_{e}=-\nabla E_{H}$ where $E_{H}$ is the redox potential (a similar relationship exists for ionic charge carriers [see Revil and Linde, 2006; Revil et al., 2009]). Inserting $\mathbf{E}_{e}=-\nabla E_{H}$ into equation (10) yields $E_{\text {emf }}=E_{H}^{(-)}-E_{H}^{(+)}$. Therefore the electromotive force is, at first approximation, the difference of the value of the redox potential at the terminal points of the battery.

[16] In identifying the electromotive force, there are two approximations that are made that are worth commenting on. The first approximation concerns the geometry of the system, where we consider here only the terminal points of the system while obviously the true distribution of the redox potential along the surface of the ore should be carefully considered (see Castermant et al. [2008] for a detailed numerical forward and inverse modeling). The second point is that we treat here the overall "potential constraint" from an ideal perspective (i.e., with no losses). For example, in the case described above, the electromotive force between electron donors and acceptors is calculated with the Nernst equation as a function of the amount of oxidized and reduced compound present in the system in the vicinity of the ore body. However, losses are known to exist between the electron donors and the ore body (and similarly between the ore body and the electron acceptors). These losses can be described by activation losses, electrolyte-resistance losses, and diffusion losses [see Bockris et al., 1970; Logan et al., 2006; Biesheuvel et al., 2009].

[17] Under the simplifying assumptions discussed above, we now explore the difference of electrical potential between two arbitrary points $\left(\mathrm{P}_{1}\right.$ and $\left.\mathrm{P}_{2}\right)$ of the conductive ground outside the ore body:

$$
\psi\left(\mathrm{P}_{1}\right)-\psi\left(\mathrm{P}_{2}\right)=\int_{P_{1}}^{P_{2}} \mathbf{E} \cdot d \mathbf{l}=\int_{P_{1}}^{P_{2}} \rho \mathbf{j} \cdot d \mathbf{l},
$$

where $\rho=1 / \sigma$ is the electrical resistivity of the ground outside the ore body (in ohm $\mathrm{m}$ ). If $\mathrm{P}_{1}$ and $\mathrm{P}_{2}$ correspond to the terminal points of the ore body and we consider only the external part of the circuit, we obtain:

$$
\psi_{(+)}-\psi_{(-)}=I \int_{(+)}^{(-)} \frac{\rho \mathbf{j} \cdot d \mathbf{l}}{I}=I R_{e},
$$

where $I$ is the electrical current crossing the surface of the ore body and $R_{e}$ is the external resistance of the ground. Note that $I$ is a dependent variable $I=I\left(E_{H} ; R_{e} ; R_{i}\right)$.

[18] We now consider the internal part of the circuit with the electromotive force. The generalized Ohm's law $\mathbf{j}=$ $\sigma\left(\mathbf{E}+\mathbf{E}_{e}\right)$ yields $\mathbf{E}=\rho \mathbf{j}-\mathbf{E}_{e}$. The difference of electrical potential between two generic points $\mathrm{P}_{1}$ and $\mathrm{P}_{2}$ is:

$$
\begin{gathered}
\psi\left(P_{1}\right)-\psi\left(P_{2}\right)=I \int_{P_{1}}^{P_{2}} \frac{\left(\rho \mathbf{j}-\mathbf{E}_{e}\right) \cdot d \mathbf{l}}{I}, \\
\psi\left(P_{1}\right)-\psi\left(P_{2}\right)=I R_{P_{1} P_{2}}-E_{e m f} .
\end{gathered}
$$

In considering the whole circuit with $\mathrm{P}_{1}$ equal to the minus pole and $\mathrm{P}_{2}$ equal to the plus pole, we obtain $E_{\text {emf }}=I\left(R_{i}+R_{e}\right)$. Inserting this relationship in equation (12), we obtain,

$$
\begin{gathered}
\psi_{(+)}-\psi_{(-)}=E_{e m f}\left(\frac{R_{e}}{R_{i}+R_{e}}\right), \\
\psi_{(+)}-\psi_{(-)}=E_{e m f}\left(\frac{1}{1+R_{i} / R_{e}}\right) .
\end{gathered}
$$


Usually the external resistance of the ground is much greater than the internal resistance of the ore body $\left(R_{e} \gg R_{i}\right)$ and therefore, the difference of electrical potential between the terminal points of the ore body is nearly equal to the electromotive force:

$$
\psi_{(+)}-\psi_{(-)} \approx E_{\text {emf }} .
$$

Using $E_{\text {emf }}=E_{H}^{(-)}-E_{H}^{(+)}$, this yields,

$$
\psi_{(+)}-\psi_{(-)} \approx E_{H}^{(-)}-E_{H}^{(+)} .
$$

Therefore measurements should show electrical potential readings that are more negative in domains characterized by high redox potentials by comparison with domains characterized by low value of the redox potential (see Timm and Möller [2001] for a laboratory example). In the case where a crust of resistive oxidation products forms at the surface of the anode (see Castermant et al. [2008] for a laboratory example), according to equation (16) the difference of electrical potential between the terminal points is expected to be always smaller than the difference of redox potential between the terminal points.

[19] Assuming $R_{e} \gg R_{i}$ holds, equation (18) demonstrates the important point that the difference of electrical potential between the terminal points is equal to minus the difference of the redox potential between these points.

\subsection{Dipolar Nature of the Self-Potential Field}

[20] Determining the electromotive force is only the first step of our analysis. The second step is to derive expressions for the electrical potential at any observation point located, for example, at the ground surface or in a borehole. In this section, we adopt the standpoint of potential field theory [Blakely, 1995], which is a classical approach used in geophysics to study quasi-static fields that can be derived from a scalar potential. The total current density is written as $\mathbf{j}=\sigma \mathbf{E}+\mathbf{j}_{S}$ where $\mathbf{E}=-\nabla \psi$ is the quasi-static electrical field, $\psi$ is the self-potential, and $\mathbf{j}_{S}=-\sigma \nabla E_{H}$ is the source current density. The continuity equation is given by equation (8). These equations together yield a Poisson equation for the electrical potential:

$$
\nabla^{2} \psi=\frac{\nabla \cdot \mathbf{j}_{S}}{\sigma}+\nabla \ln \sigma \cdot \mathbf{E}
$$

This very simple partial differential equation has two source terms on its right-hand side. The first term corresponds to the divergence of the source current density. This term is called the primary source term. The second source term corresponds to the change in the electrical potential distribution associated with heterogeneities in the distribution of the electrical resistivity. This second term corresponds to the secondary sources of electrical potential disturbances. It implies that any rigorous interpretation of the self-potential field should include a description of the electrical resistivity distribution of the medium. This information can be obtained in turn from geophysical measurements (DC-resistivity or EM-inductive methods) or by interpreting the (hydro)geological architecture of the system in terms of an electrical resistivity distribution.
[21] We note that equation (19) is also similar to the classical Poisson equation of electrostatics in a vacuum if we define an apparent charge density $\rho_{e}$ as,

$$
\begin{gathered}
\nabla^{2} \psi=-\frac{\rho_{e}}{\varepsilon_{0}} \\
\rho_{e}=-\varepsilon_{0} \frac{\nabla \cdot \mathbf{j}_{S}}{\sigma}-\varepsilon_{0} \nabla \ln \sigma \cdot \mathbf{E} .
\end{gathered}
$$

We annotate $S$ as the ground surface. We note $\Omega$ as the volume of the ore body and $\partial \Omega$ as the interface between the ore body and the surrounding porous material. The boundary condition at the ground surface (air is a perfect insulator) is $\hat{\mathbf{n}}_{S} \cdot \nabla \psi=0$, on $S$ where $\hat{\mathbf{n}}_{S}$ the outward unit vector is normal to the ground surface.

[22] We demonstrate in Appendix A that the electrical field created in the ground by an ore body is dominated mainly by the dipolar component of the field in the far field. A laboratory validation of this concept has been illustrated recently by Castermant et al. [2008]. They show that the corrosion of a metallic body in a sandbox produces both a negative self-potential pole close to the top surface of the tank and a positive self-potential pole at depth (see also Mendonça [2008] for a discussion related to the gold deposit of the Yanacocha district in Peru). The dipolar nature of the redox potential was also recognized in the sandbox experiment performed by Naudet and Revil [2005] using the power law decrease of the electrical potential with distance from the source.

\section{Biogeobattery Linear Model}

[23] Our objective in this section is to refine the model described in section 3 to account for conditions common to contaminated sites.

\subsection{Case of a Shallow, Thin, and Unconfined Contaminated Aquifer}

[24] We apply the concepts developed in section 3 to field studies of a contaminant plume located in a shallow, unconfined aquifer composed of coarse-grained sediments. In section 5, we will compare predictions based on the theory with the field data reported by Naudet et al. [2003, 2004] and analyzed later by Arora et al. [2007] and Linde and Revil [2007] for the municipal landfill of Entressen located in the south of France.

[25] In the case of a shallow plume in coarse sediments, the largest gradient in the redox potential is expected to occur across a thin (few millimeters to few decimeters in the case of Figure 3) capillary fringe right above the water table, where oxygenated water mixes with contaminated water. In a contaminant plume located in an unconfined aquifer, the decrease of the redox potential through the capillary fringe above the contaminant plume is achieved through a sequence of microbial reactions [Christensen et al., 2000]. Oxygen dissolved in water is consumed first by the aerobic microorganisms. Denitrifying bacteria then use nitrate as an electron acceptor to perform anaerobic respiration. When nitrate is depleted, reduction of manganese begins followed by the reduction of $\mathrm{Fe}(\mathrm{III})$ and the reduction of sulfate. Once 

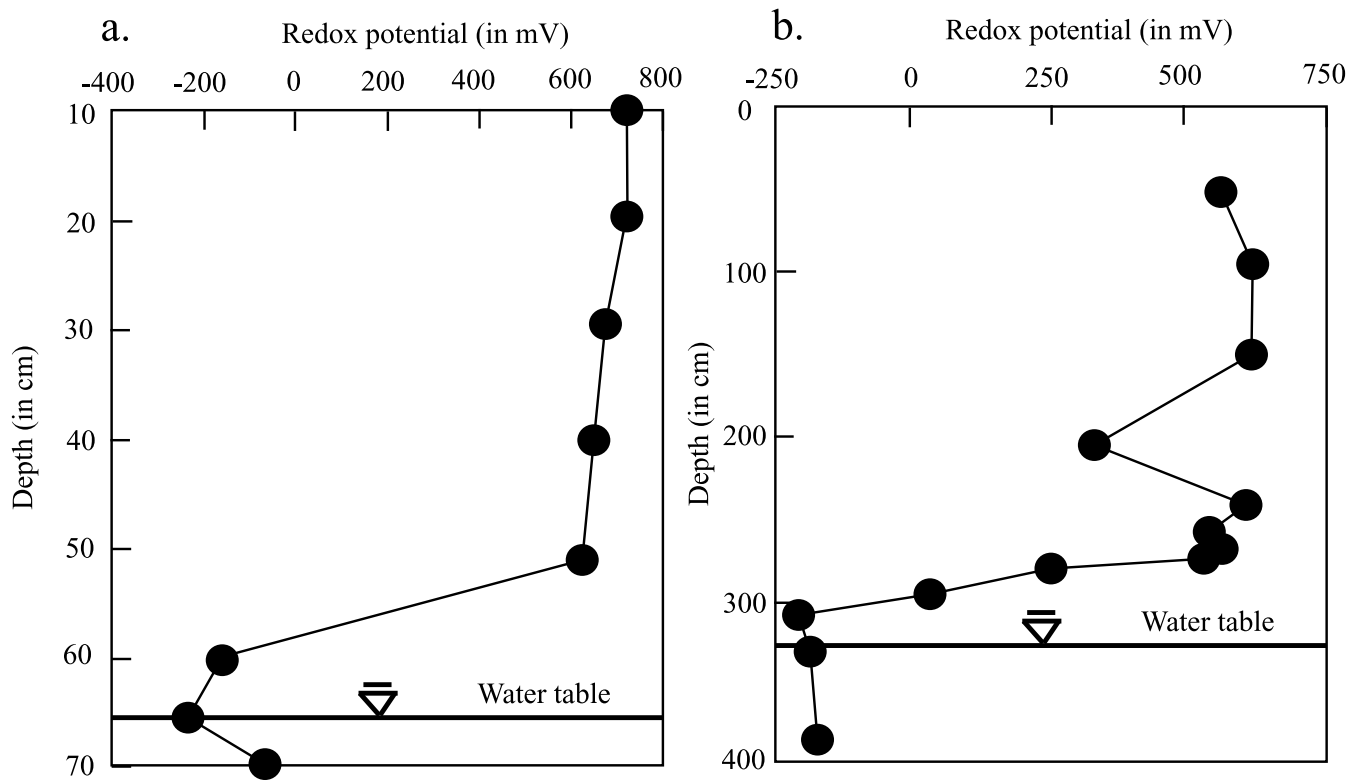

Figure 3. Vertical distribution of the redox potential above an unconfined aquifer. (a) Data from Wadey et al. [2001] in a natural soil. The redox potential was measured with platinum electrodes. The $\mathrm{pH}$ was constant with depth, and the redox potential was corrected for the potential of the calomel reference electrode $(250 \mathrm{mV})$. The redox potential values are relative to the (Fe(II), $\mathrm{Fe}(\mathrm{III}))$ couple. The transition zone between aerobic to anaerobic conditions occurs in the capillary fringe just above the water table. A similar profile can be found in the work of Ashworth and Shaw [2006]. (b) Data from Swerhone et al. [2007]. Same type of profile in fine-grained poorly graded sands. Measurements of the redox potential were performed with platinum electrodes.

all external electron acceptors are depleted, methanogenesis occurs. There may be an overlap of microbial activity within and below the capillary fringe as a result of a complex interplay between thermodynamic, kinetic, and geometric considerations [Postma and Jakobsen, 1996; Jakobsen and Postma, 1999; Jakobsen, 2007].

[26] We develop a linear model between the redox potential variations and the resulting self-potential fields. For the purposes of this study, we assume that there is an electronic conductor at the water table which is characterized by a finite value of its electrical conductivity. The potential mechanisms at the origin of such a thin and imperfect electronic conductor will be investigated in more detail in section 5 .

[27] Under conditions that exist at the Entressen Landfill, the thermodynamic force driving the transfer of electrons is distributed within a very thin layer with thickness $h$ that corresponds to the capillary fringe. We note $S$ as the surface area of this layer and we note $S_{(+)}$and $S_{(-)}$as the boundary surfaces of this thin layer, with $(+)$ characterizing the lower (anodic) boundary $(-)$ corresponds to the upper (cathodic) boundary. Because of the presence of an electronic conductor, we assume that the electrical conductivities inside and outside this layer are different. If $\sigma_{(-)}, \sigma_{h}$, and $\sigma_{(+)}$denote the electrical conductivity of the vadose zone, the thin layer, and the aquifer, respectively, we expect to have $\sigma_{h}>\sigma_{(+)}>$ $\sigma_{(-)}$. We note $\hat{\mathbf{n}}$ the normal unit vector to the thin layer described above and we assume that the normal component of the thermodynamic force driving the transfer of electrons is positive if it has the same direction as $\hat{\mathbf{n}}$.
[28] It is convenient to represent the current density as a system of elementary current tubes with infinitesimally small cross sections and thicknesses. Each of the current tubes behaves as a small dipolar generator according to the theory developed in section 2 . Taking into account that the source volume is very thin, the field $\mathbf{E}_{e}=-\nabla E_{H}$ does not change and therefore,

$$
E_{\text {emf }}=\int_{(+)}^{(-)} \mathbf{E}_{e} \cdot d \mathbf{l}=h E_{n}^{e},
$$

where $E_{n}^{e}$ is the normal component of $\mathbf{E}_{e}$ and $h$ is the thickness of the source of current. In addition, because $h$ is very small, we can safely consider then that the internal resistance of each element of this layer is negligible with respect to the external resistance $R_{e}$. Using equation (16) with $R_{\mathrm{i}} \ll R_{e}$ yields $\psi_{(+)}-\psi_{(-)} \approx E_{\text {emf }}$. Therefore the difference of the electrical (self-) potential across the water table is equal to the electromotive force acting near the same terminal points. The dipole moment is $P=\varepsilon_{0} E_{\text {emf }}=\varepsilon_{0} h E_{n}^{e}$.

[29] The distribution described above is called a double layer distribution in potential field theory [Blakely, 1995]. We consider the limiting case $h \rightarrow 0$ (infinitesimally thin source body) and $E_{n}^{e} \rightarrow \infty$ (the gradient of the redox potential is so sharp that its derivative is infinite). The dipole moment $P$ remains, however, finite. The negative charge is located above the water table and the positive charge below the water table because of the gradient in the 
redox potential. The boundary-value problem for the selfpotential is given by,

$$
\begin{gathered}
\psi_{(+)}-\psi_{(-)}=E_{\text {emf }}^{c} . \\
\sigma_{(+)} \frac{\partial \psi_{(+)}}{\partial n}-\sigma_{(-)} \frac{\partial \psi_{(-)}}{\partial n}=0 \\
\frac{\partial \psi_{(+)}}{\partial t}-\frac{\partial \psi_{(-)}}{\partial t}=\frac{\partial E_{e m f}^{c}}{\partial t}
\end{gathered}
$$

where $n$ and $t$ represent the normal and tangential derivatives with respect to the position of the water table, respectively, and $E_{\text {emf }}^{c}$ is the contact electromotive force.

[30] From here, we neglect the effect of the contrast in resistivity. Therefore $\sigma_{(+)}=\sigma_{(-)}$in equation (24). This assumption is made to focus, like in section 2 , on the primary driving (source) mechanism. Looking for a firstorder solution of the previous set of equations, we rewrite the expression of the extraneous force and the electromotive force as a function of the redox potential,

$$
\begin{gathered}
\mathbf{E}^{e}\left(\mathbf{r}^{\prime}\right)=-\nabla E_{H}\left(\mathbf{r}^{\prime}\right)=-\left[E_{H}^{(-)}-E_{H}^{(+)}\right] \delta\left(\mathbf{r}^{\prime}-\mathbf{r}_{W}\right), \\
E_{\text {emf }}=\int_{(-)}^{(+)} \mathbf{E}^{e} \cdot d \mathbf{l}=E_{H}^{(+)}-E_{H}^{(-)},
\end{gathered}
$$

where $\mathbf{r}_{W}$ describes the position of the water table and $\delta(\mathbf{r})$ is the delta function defined by $\delta\left(\mathbf{r}^{\prime}-\mathbf{r}_{W}\right)=0$ for $\mathbf{r}^{\prime} \neq \mathbf{r}_{W}$ and $\delta\left(\mathbf{r}^{\prime}-\mathbf{r}_{W}\right)=1$ for $\mathbf{r}^{\prime}=\mathbf{r}_{W}$. Using the Green method of integration, the electrical potential located at an observation point $P(\mathbf{r})$ is given by,

$$
\psi(\mathbf{r})=\frac{1}{4 \pi} \int_{\partial \Omega}\left(E_{H}^{(+)}-E_{H}^{(-)}\right)\left(\frac{\mathbf{r}-\mathbf{r}_{W}}{\left|r-r_{W}\right|^{3}}\right) \cdot d \mathbf{a},
$$

where $d \mathbf{a}$ describes a surface element of the water table $\partial \Omega$. To obtain an analytical solution of the problem, we consider (1) that the redox potential in the vadose zone is constant, (2) under the assumption of a constant activity of the reducing species with depth in the aquifer, the redox potential of the aquifer varies only with the position $(x, y)$ but not with depth (again to emphasize the contribution at the water table), and (3) that outside the contaminant plume there is no sharp gradient of the redox potential through the water table. With these assumptions, the electrical potential can be described by,

$$
\psi(\mathbf{r}) \approx \frac{1}{4 \pi}\left(E_{H}-E_{H}^{r e f}\right) \int_{\partial \Omega}\left(\frac{\mathbf{r}-\mathbf{r}_{W}}{\left|r-r_{W}\right|^{3}}\right) \cdot d \mathbf{a},
$$

where $E_{H}$ and $E_{H}^{r e f}$ stand for the redox potential of the aquifer below the measurement station and below the reference self-potential station, respectively. The integral in equation (29) corresponds to the solid angle $\omega$ from which the source body is seen from each self-potential station P:

$$
\omega=\int_{\partial \Omega}\left(\frac{\mathbf{r}-\mathbf{r}^{\prime}}{\left|r-r^{\prime}\right|^{3}}\right) \cdot d \mathbf{a} .
$$

In the case where the conductive ground corresponds to a half-conducting space, the solid angle is $2 \pi$ (a half-space in three dimensions with an upper boundary in contact with an insulating body). Therefore we come to the conclusion that a first-order approximation of the self-potential problem in this case is:

$$
\psi \approx \frac{1}{2}\left(E_{H}-E_{H}^{r e f}\right) .
$$

We show in section 5.1 that equation (31) describes the selfpotential response of a shallow organic contaminant plume. This model implies that the self-potential should be more positive in the plume that outside. There are very few measurements inside contaminant plumes of the selfpotential in boreholes and performed right after the completion of the well. Greenhouse and Harris [1983] showed the case of a contaminant plume where the plume itself is characterized at depth by a positive self-potential anomaly (see Figure 4) in agreement with our prediction.

\subsection{Other Contributions}

[31] An expression of the source current density associated with the gradient of the activity of the electrons through an electronic conductor is,

$$
\mathbf{j}_{S}=\frac{k_{b} T}{e} \sigma \nabla \ln \left\{\mathrm{e}^{-}\right\},
$$

which is consistent with both equation (9) with $\mathbf{E}_{e}=-\nabla E_{H}$ and equation (2) with $p \varepsilon=-\log \left\{\mathrm{e}^{-}\right\}$. Similar terms can be written for the other charge carriers, anions and cations [Revil and Linde, 2006]. The Hittorf number of a charge carrier, at any given scale, corresponds to the fraction of the electrical current that is carried by this charge carrier at this scale. At the scale of a porous material, the macroscopic Hittorf numbers have contributions from the bulk pore water phase and through the electrical diffuse layer at the pore water interface [see, e.g., Revil, 1999]. According to the model developed by Revil and Linde [2006, equation (182)] and neglecting the contribution of the diffuse layer in the vicinity of the pore surface upon the macroscopic Hittorf numbers, the source current density associated with $N$ ionic species is,

$$
\mathbf{j}_{S}=-k_{b} T \sum_{i=1}^{N} \frac{t_{i} \sigma}{q_{i}} \nabla \ln \{i\},
$$

where $q_{i}$ is the charge of species $\mathrm{i}, t_{\mathrm{i}}$ is the microscopic Hittorf number of the ionic species $i$ in the pore water, $\sigma$ is the total electrical conductivity of the porous material, and $\{i\}$ represents the activity of the ionic species i. The microscopic Hittorf numbers can be computed from the concentrations and mobilities of the various charge carriers that are present in the pore water [Revil, 1999]. 


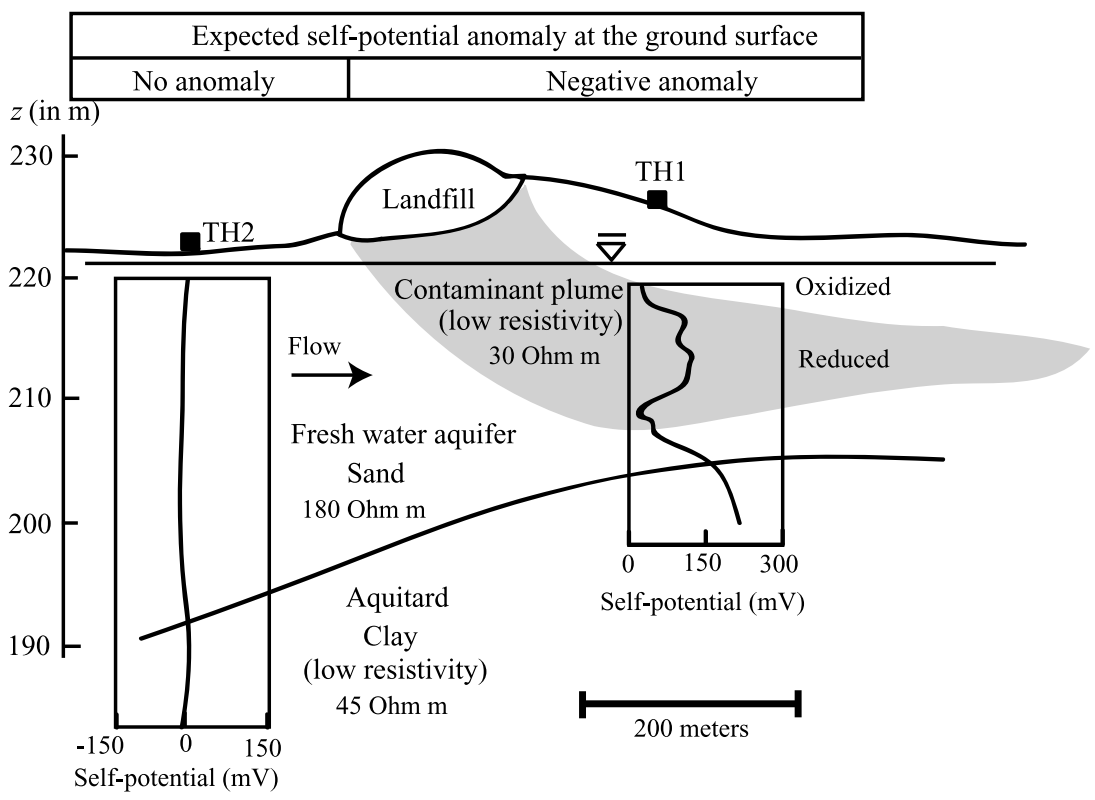

Figure 4. Sketch of self-potential logs performed just after the completion of drilling. TH2 is a well located upstream to the landfill while TH1 crosses the contaminant plume. Note the positive self-potential anomaly inside the contaminant plume (well TH1) while there is no vertical self-potential anomaly upstream in TH2. Modified from Greenhouse and Harris [1983]. The cause of the large anomaly below the plume may be due to a drop in the gradient of the chemical potential of the ionic species between the clay material and the sand (see Revil et al. [2005], who analyzed this type of electrical potential difference with a Donnan equilibrium model).

[32] In a system where there is transfer of both types of charge carriers, electrons and ions, equations (32) and (33) can be generalized as,

$$
\mathbf{j}_{S}=-k_{b} T \sum_{i=1}^{N+1} \frac{t_{i} \sigma}{q_{i}} \nabla \ln \{i\},
$$

where the sum is extended to $N$ ionic species plus the electrons. The microscopic Hittorf number of the electron represents the fraction of the total current transported by the electrons and can be defined from a model of electronic conduction inside the pore space of the porous material like the conductive pili of bacteria as discussed below. However, if there is a competition between electrons and anions, the contribution of the electrons is expected to be dominant because the mobility of the electrons in an electronic conductor is expected to be much higher than the mobility of the ions in the pore water (we do not know however if this is true in a biotic electronic conductor, see section 5). Therefore the Hittorf number of the electron is expected to be close to one and therefore we recover equation (32) when an electronic conductor is present. In this case, we expect large self-potential anomalies.

[33] In the case where there are no electronic conductors, we recover equation (33) and the self-potential signals are expected to be weak. The magnitude of the self-potential anomalies if only ions are transferred inside a porous material without an electronic conductor has been analyzed in detail by Revil et al. [2009]. A summary of their results can be found in Figure 5. These authors ran a set of experiments in which a geobattery was generated using electrolysis reactions of a pore water solution containing iron. A DC power supply was used to impose a difference in electrical potential of $3 \mathrm{~V}$ between a working platinum electrode (anode) and an auxiliary platinum electrode (cathode). Both electrodes inserted into a tank filled with a well calibrated sand infiltrated by a $(0.01 \mathrm{Mol} / \mathrm{L} \mathrm{KCl}+$ $0.0035 \mathrm{Mol} / \mathrm{L} \mathrm{FeSO}_{4}$ ) solution. After the direct current was turned off, they followed the $\mathrm{pH}$, the redox potential, and the self-potential at several time intervals. The self-potential anomalies amounted to a few tens of millivolts after the current was turned off and decreased over time. After several days, all the redox-active compounds produced initially by the electrolysis reactions were consumed through chemical reactions and the self-potential anomalies fell to zero. This experiment shows that only small selfpotential anomalies (less than $20 \mathrm{mV}$ ) are generated in this case despite a strong gradient in the redox potential $(>600 \mathrm{mV})$ and the presence of iron in the pore water. The readers are also directed to the experiments proposed by Maineult et al. [2006]. These experiments provide the same order of magnitude for the self-potential signals measured in the absence of an electronic conductor.

[34] The observations made by Revil et al. [2009] and Castermant et al. [2008] imply that an electronic conductor should be present to generate strong self-potential signals observed in some case studies. This implies that small selfpotential anomalies require no electronic conductors to bridge electron donors and electron acceptors. This seems to be the case for a number of field observations for contaminant plumes for which only modest self-potential anomalies were reported in the field despite strong gradients in the redox potential [Weigel, 1989; Hämmann et al., 1997; Vichabian et al., 1999]. In these cases, we believe that these anomalies are related directly to the gradient of the chemical 


\section{a. Experimental setup}

Generator

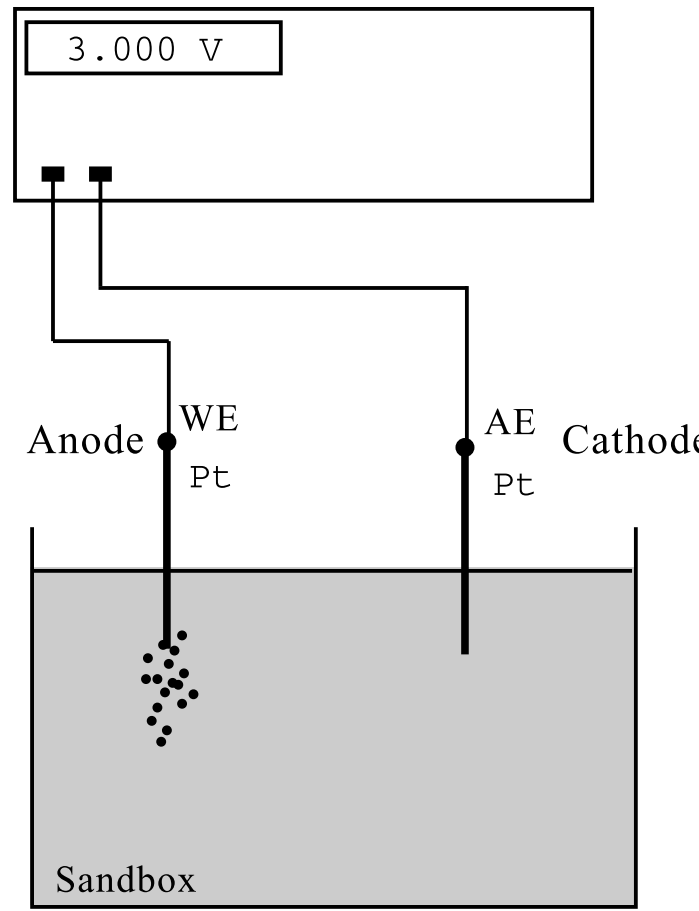

\section{b. Anode}

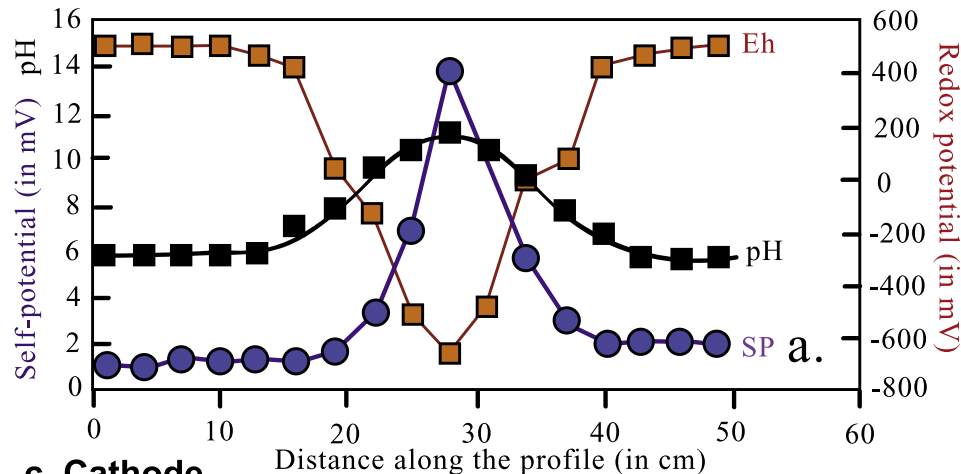

c. Cathode Distance along the profile (in $\mathrm{cm}$ )

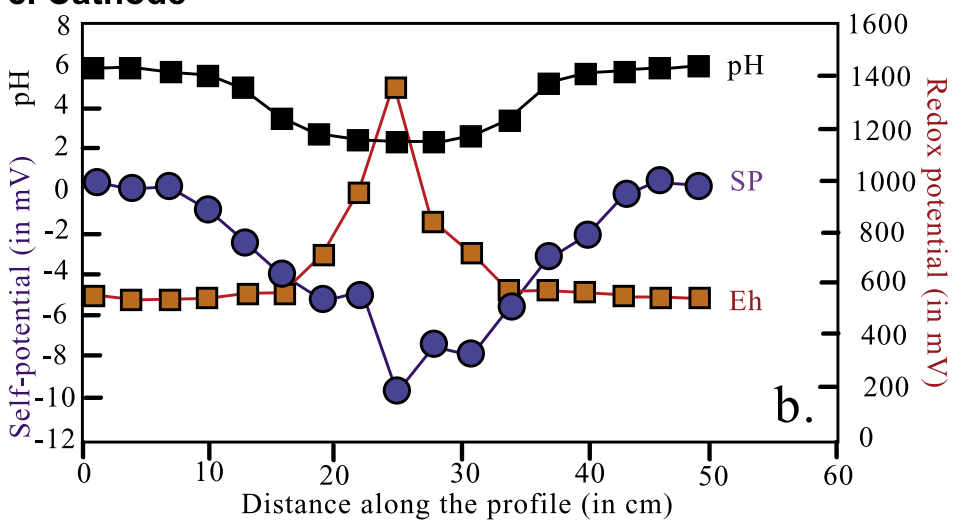

Figure 5. Self-potential anomaly, redox potential anomaly, and $\mathrm{pH}$ anomaly created in a sandbox without an electronic conductor. (a) The sandbox was filled with a well calibrated sand saturated by a solution composed of ultrapure water $\left(18 \mathrm{M} \Omega\right.$, ultraviolet treatment) and $0.01 \mathrm{Mol} \mathrm{L}^{-1} \mathrm{KCl}\left(\mathrm{Labosi}{ }^{\mathbb{R}}\right)$, $0.0035 \mathrm{Mol} \mathrm{L}{ }^{-1} \mathrm{FeSO}_{4}\left(\operatorname{Labosi}^{\mathbb{R}}\right)$, and $135 \mu \mathrm{L} \mathrm{L}^{-1}$ of formaldehyde (Sigma ${ }^{\mathbb{R}}$ ). Formaldehyde was added to the electrolyte to prevent development of bacteria. The system was kept quiet during $12 \mathrm{~h}$ to allow self-compaction of the sand. Then the applied voltage of $3 \mathrm{~V}$ was maintained during 6 days [from Revil et al., 2009]. (b, c) The self-potential was measured at the top surface of the tank with a $\mathrm{Ag} / \mathrm{AgCl}$ with respect to reference $(\mathrm{Ag} / \mathrm{AgCl})$ electrode is located at $x=0$. The measurements were taken after the shutdown of the electrical current. Despite a very strong difference of redox potential, the self-potential anomaly is relatively small. The $\mathrm{pH}$ is reported in $\mathrm{pH}$ units.

potential of the ionic charge carriers and not to a biogeobattery process. However, additional experiments are required to confirm these results in the case of clayey soils with high concentrations of $\mathrm{Fe}$ oxides and Fe-bearing phylosilicate phases.

\section{Comparison With Available Data}

[35] In this section, we compare the predictions of our model with self-potential responses associated with four different published laboratory and field environmental studies.

\subsection{Entressen Case Study}

[36] The case of the landfill of Entressen, in the south of France, is probably the most documented in terms of a relationship between the self-potential and the redox potential. Field observations were first provided by Naudet et al. [2003, 2004]. A self-potential map, downstream the landfill of Entressen, is shown in Figure 6. It shows a strong selfpotential anomaly of several hundred millivolt above the oxic portion of the aquifer. A forward numerical model was developed by Arora et al. [2007]. Using this model, Linde and Revil [2007] developed an inversion algorithm of the self-potential data to determine the distribution of the redox potential inside the contaminated portion of the aquifer.

[37] Entressen is truly a textbook case because the contaminants are constrained within a shallow aquifer (few meters below the ground surface with a thickness of $2 \mathrm{~m}$ ) and are spread several kilometers down gradient from the landfill. The presence of carbonate rocks buffers the $\mathrm{pH}$, and the capillary fringe is thin and therefore the gradient of the redox potential through the water table very high. Two subsurface metallic pipes cross through the field; however, because their influence on the self-potential field was cumulative and localized, it was easy to remove their effect from the dense self-potential measurements (see Naudet et al. [2004] for details). Once the pipes and the contribution related to the flow of the groundwater had been removed [Naudet et al., 2004], the residual self-potential anomaly exhibits the following linear relationship with the redox potential measured at depth (see Figure 7),

$$
\psi \approx a\left(E_{H}-E_{H}^{r e f}\right)
$$

where $a=0.50 \pm 0.04$ [Naudet et al., 2004; Arora et al., 2007], $E_{H}$ is the redox potential below the self-potential 


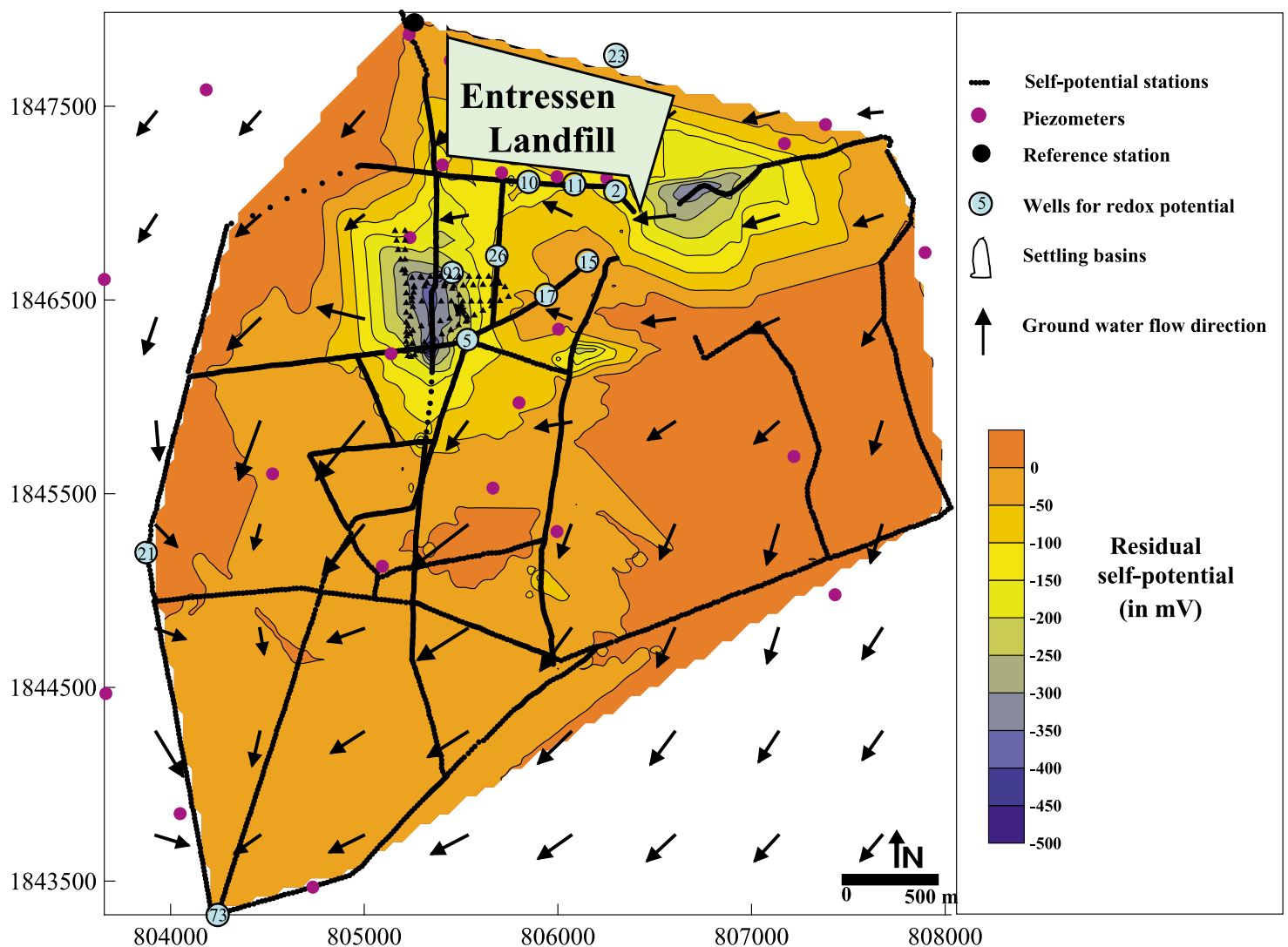

Figure 6. Residual self-potential map downstream the Entressen landfill after removal of the pipes signature and the self-potential contributions related to groundwater flow [see Arora et al., 2007]. The small circles with numbers represent the wells in which the redox potential was measured with platinum electrodes. The other solid circles correspond to wells where the piezometric levels were determined. The arrows indicate the piezometric gradient and hence the groundwater flow direction.

station where $\psi$ is measured (measured in a piezometer), and $E_{H}^{\text {ref }}$ is the redox potential in the aquifer below the selfpotential station used as a reference for establishing the selfpotential map. The redox potentials were measured with platinum electrodes and are therefore mainly representative of the ferrous-ferric activity ratio. Equation (35), resulting from field measurements, is in agreement with equation (31) resulting from our model.

[38] Figure 8 shows how a geobattery could work at the water table in the presence of a contaminant plume like at the Entressen landfill. If the capillary fringe is thin, the water table is characterized by a strong gradient in the value of the redox potential above the contaminant plume by comparison with a vertical profile located upstream. It follows that if an electronic conductor is located at this position, the capillary fringe of the contaminated portion of the aquifer can be the setting of an electron transfer mechanism. Such a battery generates a dipolar self-potential field. This model predicts a change in the polarity of the residual self-potential (the measured self-potential minus the contribution related to groundwater flow) through the capillary fringe.

\subsection{Portadown Case Study}

[39] We present now the case of a former manufactured gas plant in Portadown, Northern Ireland, in order to study the dipolar nature of the self-potential field associated with

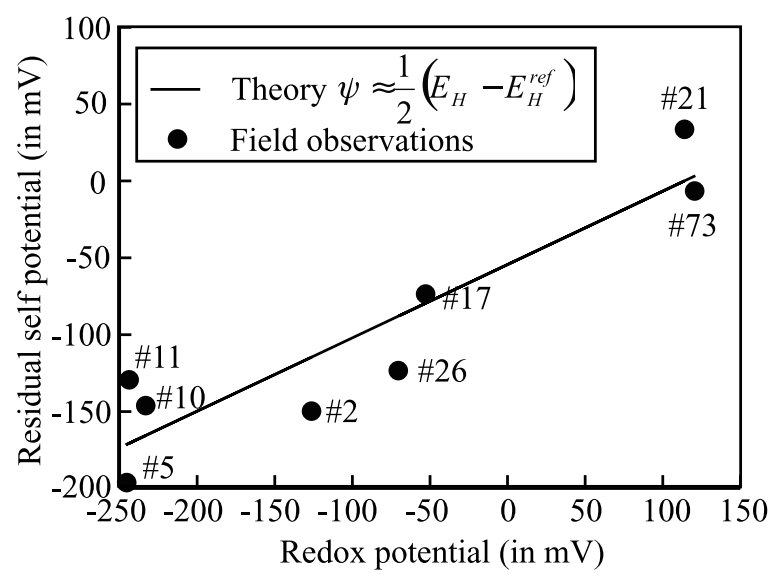

Figure 7. Comparison between the Entressen field data (the solid circles) and the first-order relationship derived in the main text (the numbers represent the label of the wells shown in Figure 3, $\mathrm{R}=0.91$ ). The self-potential is measured at the ground surface and has been corrected for the streaming potential contribution associated with the flow of the groundwater. Note that the self-potential signals amount to several hundreds of millivolts and that the line does not represent a fit to the measured field data, but rather the slope of the trend based on theory (modified from Arora et al. [2007]). 
a.

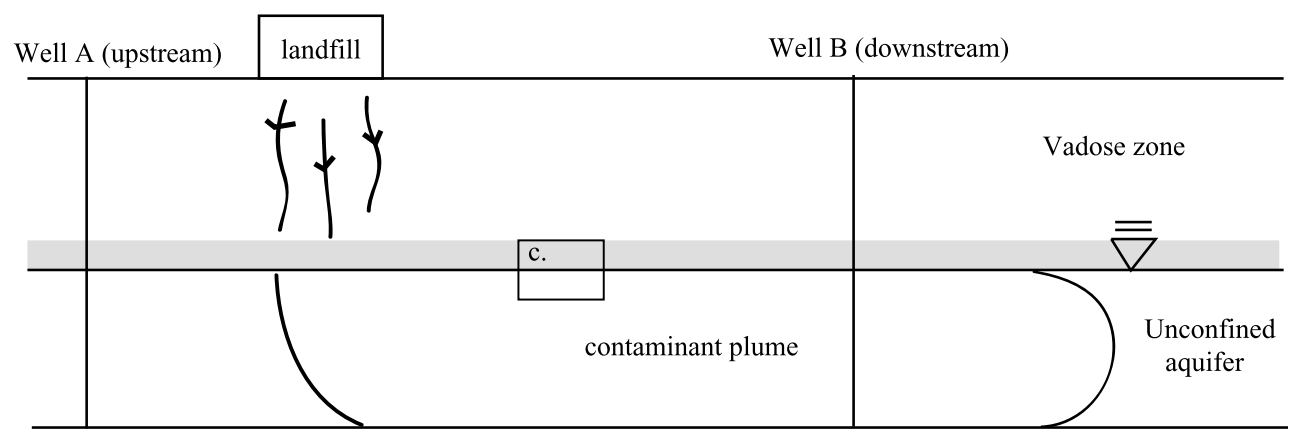

Clay aquitard
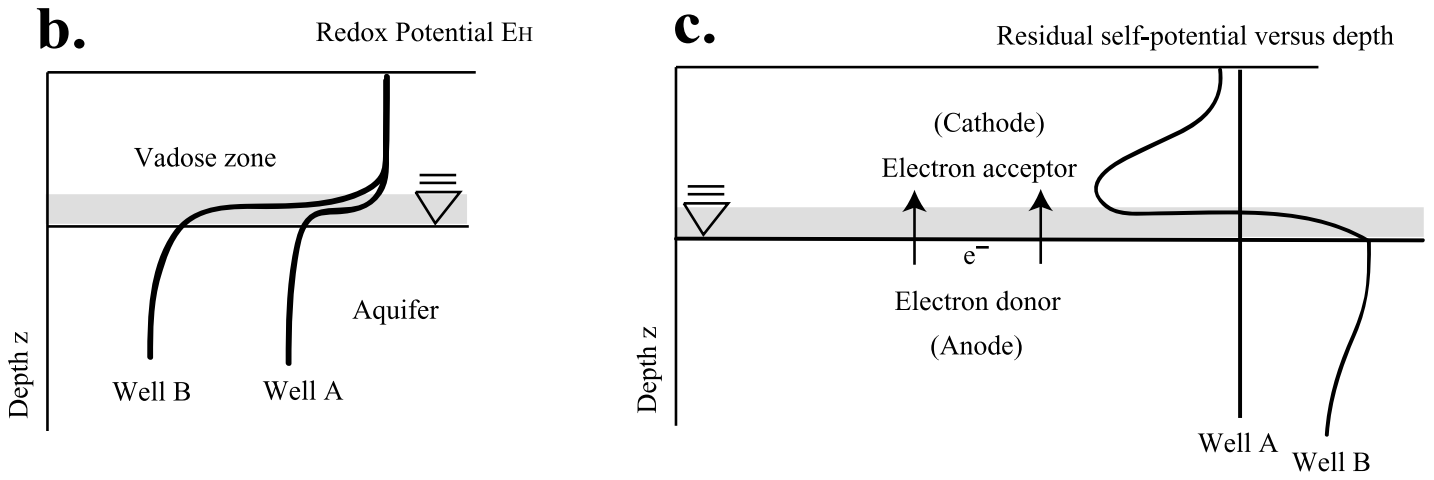

Figure 8. Sketch of the geobattery associated with a contaminant plume. (a) Leachates from a landfill are responsible for a contaminant plume in an unconfined aquifer. (b) There is a stronger gradient of the redox potential through the capillary fringe (the gray area) above the contaminant plume by comparison with the profile shown upstream. (c) The capillary fringe of the contaminated portion of the aquifer is potentially the setting of an electron transfer mechanism normal to the water table. This battery is generating a dipolar self-potential field. This model predicts a change in the polarity of the residual selfpotential (the measured self-potential minus the contribution related to groundwater flow) through the capillary fringe (see Figure 4 for a field example).

the presence of a redox front. The decommissioning of this plant left a legacy of widespread organic (e.g., mineral oils, PAHs, BTEXs, creosols, phenols) and inorganic (e.g., cyanide, ammonical nitrogen, elemental sulfur) groundwater and soil contamination [Doherty, 2002; Ferguson et al., 2003]. Fifty boreholes and trial pits dug at the site revealed that the contamination is concentrated in a heterogeneous mixture of ground, peat, and alluvial deposits, some eleven meters thick, that form a series of aquifers (hydraulic conductivity of $\sim 10^{-4}$ to $10^{-5} \mathrm{~m} \mathrm{~s}^{-1}$ ) and aquitards (hydraulic conductivity of $\sim 10^{-6}$ to $10^{-9} \mathrm{~m} \mathrm{~s}^{-1}$ ), underlain by low permeability and thick clay-rich glacial tills (hydraulic conductivity of $\sim 10^{-13} \mathrm{~m} \mathrm{~s}^{-1}$ ). The free phase of the contamination transported with the groundwater flow at the site is contained by a bentonite slurry wall and remediated using a biological Permeable Reactive Barrier (PRB) [Doherty et al., 2006; Davis et al., 2006].

[40] Detailed surface and borehole-based geophysical, geochemical and microbiological data sets were collected as part of a comprehensive program of site investigation [Kulessa et al., 2006]. Here we report on representative electrical resistivity and self-potential data. The self-potential data were collected using lead-lead chloride electrodes [Petiau, 2000] on a $5 \mathrm{~m}$ by $5 \mathrm{~m}$ grid spanning both contaminated and uncontaminated sectors of the site. The reference electrode was located in the uncontaminated sector, and all self-potential measurements were made using a METRA HIT 22S high-impedance multimeter. At each measurement station (including that of the reference electrode) a spade-deep hole was dug and filled with viscous bentonite to ensure identical electrode coupling to the ground everywhere on site.

[41] A representative resistivity tomogram (Figure 9a) crossing the most polluted sector of the site is characterized by a deeper-seated resistive anomaly (resistivity $>\sim 100 \Omega \mathrm{m}$ centered around $\sim 26 \mathrm{~m}$ in Figure $9 \mathrm{a}$ ) and a shallower conductive anomaly (resistivity $<\sim 5 \Omega$ m centered around $\sim 14 \mathrm{~m}$ in Figure 9a) that are electrically distinct from relatively uncontaminated ground (as confirmed by boreholes and trial pits) to the west (right side of Figure 9a; resistivity between $\sim 10 \Omega \mathrm{m}$ and $\sim 50 \Omega \mathrm{m}$ west of $x \sim 36 \mathrm{~m}$ ). Trial pits dug in the areas characterized by the resistivity anomalies, together with contaminant modeling [Doherty, 2002 ], revealed that the resistive anomaly centered around $x \sim 26 \mathrm{~m}$ in the tomogram (Figures $9 \mathrm{a}$ and $9 \mathrm{~b}$ ) corresponds to an anaerobic free-phase plume of organic and inorganic contamination below the groundwater table. The conductive anomaly centered around $x \sim 14 \mathrm{~m}$ corresponds to a fully 


\section{a. Resistivity tomogram (profile R2)}

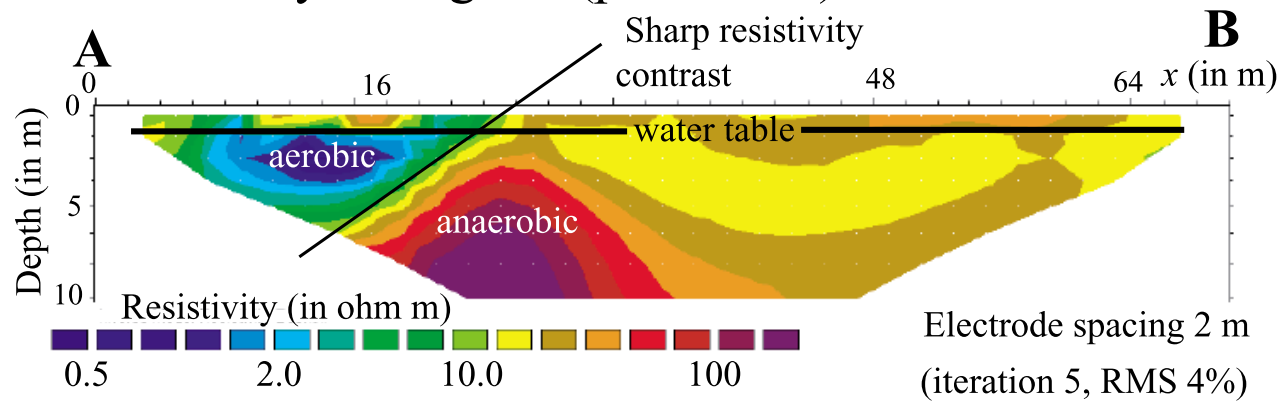

\section{c. Self-potential map (corrected for ground water flow)}

\section{b. Ground truth}
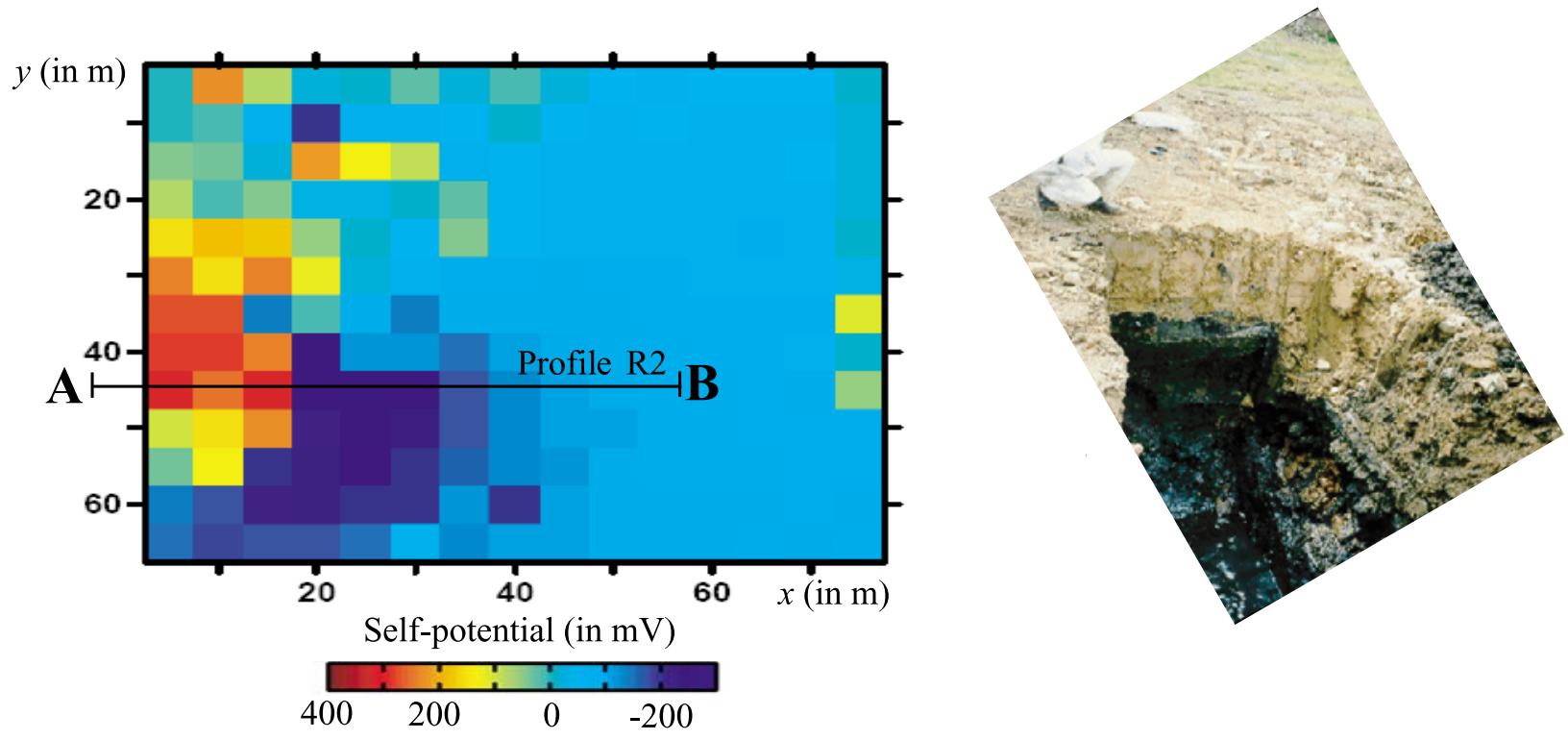

Figure 9. Resistivity tomogram, residual SP map (corrected for groundwater-flow induced streaming potentials, as explained in the text), and photograph of a trial pit dug in the area of the resistive anomaly. (a) Representative resistivity tomogram, characterized by a deeper-seated resistive anomaly centered on $x \sim 26 \mathrm{~m}$, and a shallower conductive anomaly centered on $x \sim 14 \mathrm{~m}$; the contact between the two resistivity anomalies is inferred to separate zones dominated by aerobic and anaerobic conditions. (b) Photograph of a trial pit dug in the area of the resistive anomaly (note the person in the left-hand corner for scale). (c) The residual self-potential map is dominated by a dipolar anomaly in the northeastern sector of the site (line $\mathrm{AB}$ represents the resistivity profile).

saturated aerobic lens of man-emplaced materials (black ashy clinker, fused iron lumps, organic gasworks waste [Doherty, 2002]), perched above a localized layer of clay acting as an aquiclude. Significantly for the present study, the sharp resistivity contrast between the shallow conductive anomaly and the deeper-seated resistive anomaly (Figure 9a) can thus be inferred to coincide spatially with a contact zone between aerobic conditions to the east and an anaerobic conditions to the west.

[42] The self-potential data were corrected for groundwaterflow induced streaming potentials using the methodology proposed by Naudet et al. [2003, 2004]. The residual selfpotential map reflects electrochemically and biologically generated self-potential signals. The residual map is dominated by a strong dipolar self-potential anomaly (Figure 9c). The approximated line of zero-crossing of the residual dipolar anomaly $(-456 \mathrm{mV}$ to $+379 \mathrm{mV}$; Figure 9c) coincides spatially with the aerobic-anaerobic contact zone. 3-D cross-correlation tomography [Crespy et al., 2008] revealed that the positive self-potential pole is located at $\sim 19$ m depth at the western limit of the prominent conductive anomaly (Figure 9a). The negative self-potential pole is located at $x \sim 26 \mathrm{~m}$ depth at the top of the prominent resistive anomaly (Figure 9a) [Kulessa et al., 2006]. This study demonstrates therefore the dipolar nature of the selfpotential field in such a case.

\subsection{Berre Case Study}

[43] It has been observed that strong self-potential anomalies exist over areas of petroleum seepage [Thompson et al., 1997]. The case study we discuss below is related to the amplitude of self-potential anomalies over a biode- 


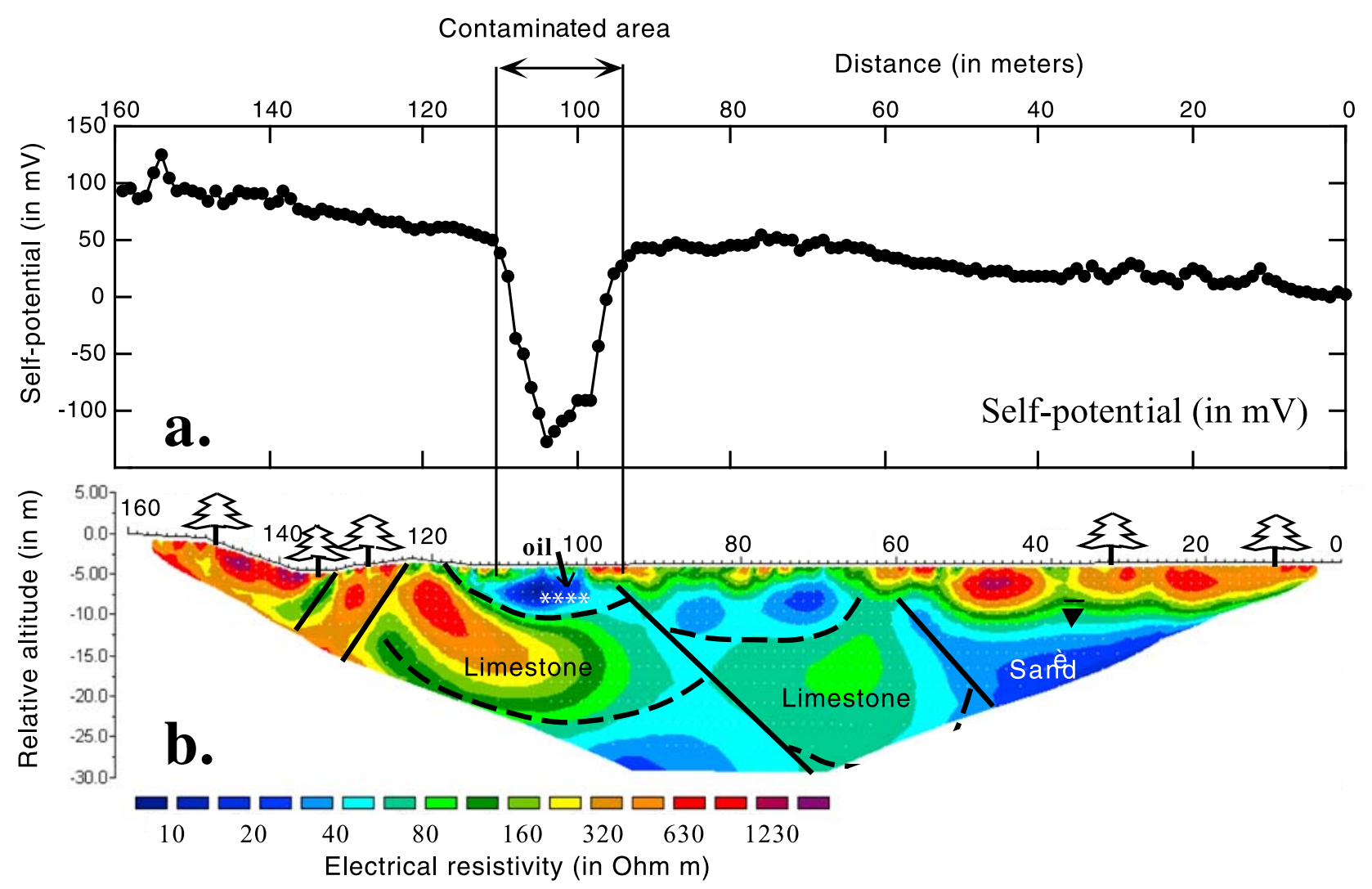

Figure 10. Self-potential anomaly associated with an oil spill in the south of France. (a) Self-potential profile. The self-potentials have been measured with two Petiau electrodes at the ground surface (the reference electrode is located at $x=0$ on the right-hand side of the profile). The direction of the oil spill is normal to profile. The position of the self-potential anomaly is perfectly correlated with the position of the oil spill, which has been recognized by shallow piezometers. Note the self-potential anomaly amounts $-160 \mathrm{mV}$. (b) Electrical resistivity tomography profile (take out: $2.5 \mathrm{~m}$, Wenner- $\alpha$ array, RMS error $3.2 \%$ ) showing the distribution of electrical resistivity and interpreted faults and lithofacies.

graded oil spill. Figure 10 shows the self-potential profile collected normal to an oil spill, where biodegradation of the oil is taking place. This site is located near a refinery at Berre in the south of France. The self-potential profile shows a distinct anomaly of $-160 \mathrm{mV}$ where the oil spill is located. There are no pipes in the ground in this area, so the self-potential anomaly does not result from the corrosion of a metallic body. This type of self-potential anomaly associated with the biodegradation of oil offers a promising nonintrusive method of detection for these spills. The amplitude of this anomaly is not compatible with a source associated with the distribution of the chemical potentials of the ionic species. We cannot rule out however the possibilities of electron transfer through Fe-oxide or Fe-bearing phyllosilicates.

\subsection{Laboratory Experiments}

[44] In this section, we compare our theoretical predictions with self-potential measurements made in both sandbox and column-based laboratory setups. We first reinvestigate the sandbox experiments described by Naudet and Revil [2005]. In this experiment, a small region of a thin Plexiglas tank was filled with tap water saturated sand and was treated with sulfato-reducer bacteria and organic nutrients. Redox potential measurements were performed both in the treated portion of the tank containing the bacteria and in the nontreated portion of the tank used as a reference. Timelapse self-potential signals were recorded at the upper (free-air) surface of the tank. Another controlled sandbox experiment was carried out without the contaminant plume. In the sandbox treated with the contaminant plume, Naudet and Revil [2005] observed a linear correlation between the temporal variations of these self-potential signals and the redox potential difference between the treated and the nontreated portions of the tank. Their relationship is $\psi \approx$ $a\left(E_{H}-E_{H}^{r e f}\right)$ with $a=0.20 \pm 0.04$. For a 2-D space, the relationship between the self-potential signals and the distribution of the redox potential given by equation (31) needs to be modified according to,

$$
\psi \approx \frac{\omega}{2 \pi}\left(E_{H}-E_{H}^{r e f}\right)
$$

where $\psi$ is the electrostatic potential for an electrode located just above the source (with respect to a reference electrode located far from the source), $2 \pi$ represents the $2-\mathrm{D}$ solid angle of the total space for a 2-D tank and $\omega$ is the solid angle of the source (electrode number 3 in the experiment by Naudet and Revil [2005]). From their experimental setup, we obtain $\omega \approx \pi / 3$. Using equation (36), this yields 

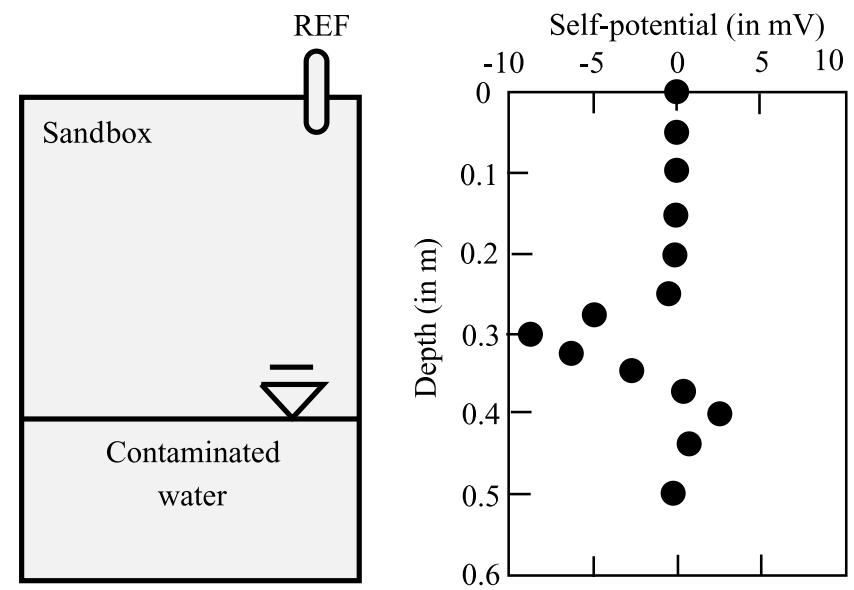

Figure 11. Distribution of the self-potential 9 days after inoculation of a sandbox with $p$. putida and mineral oil. The self-potential vertical profile shows a dipolar anomaly just above the water table: negative above the water table and positive below.

$\psi \approx a\left(E_{H}-E_{H}^{r e f}\right)$ with $a=0.18 \pm 0.05$ in good agreement with the trend discussed above $(a=0.20 \pm 0.04)$.

[45] Next, we discuss the experimental results reported by Ntarlagiannis et al. [2007]. They used a sand column and the metal reducing bacterium Shewanella oneidensis MR-1 investigated extensively by Gorby et al. [2006]. The top of the column was loosely covered. They detected, after a period of $250 \mathrm{~h}$ (10.4 days), a strong self-potential signal of $+602 \pm 4 \mathrm{mV}$ between an electrode located in the top of the column and the reference electrode located at the bottom of the column. Ntarlagiannis et al. [2007] interpreted the magnitude and the duration of the self-potential anomaly to be controlled by the electron donor availability (lactate) and the nanowire building process. "Nanowire" is a term used to describe external pili of bacteria that may be used to transfer electrons [Reguera et al., 2005; Gorby et al., 2006]. These pili are hair-like protein rods that extend from the bacteria. Despite the fact that Shewanella is a facultative adaptative bacterium, Shewanella forms nanowires only when terminal electron acceptors are limiting.

[46] A control column experiment was also performed by Ntarlagiannis et al. [2007] with a Shewanella oneidensis mutant strain that was deficient in the MtrC and OmcA gene complex, which resulted in cells with deficient pili [Gorby et al., 2006; Ntarlagiannis et al., 2007]. Removing the $\mathrm{MtrC}$ and OmcA gene complex results in cells that cannot reduce $\mathrm{Fe}$ or $\mathrm{Mn}$. In the case of the mutants, a minimal selfpotential anomaly $( \pm 10-15 \mathrm{mV})$ was observed in this control column experiment. This excludes any electrodic effects associated with the electrochemistry of the electrode surface. Nonetheless, because these results remain debatable, we suggest that the experiments should be repeated using capacitive electrodes that are known to be inert.

[47] The experiments reported by Ntarlagiannis et al. [2007] suggest that bacteria pili may be needed for the geobattery to operate. This hypothesis, together with our general considerations of biotic processes associated with contaminant plumes, has led us to coin the term biogeobattery for this concept. Indeed, these results seem to rule out the assumption that only abiotic mechanisms (like in the case of ore bodies) can explain the field data. The role of bacteria in this process is further investigated in section 6 .

[48] The last experiment we report is a preliminary experiment aimed at investigating the dipolar nature of the electrical field at the water in the presence of bacteria. The experimental setup is shown in Figure 11, the height of the sandbox was $60 \mathrm{~cm}$. The grain diameter of the sand was in the range $0.6-1.0 \mathrm{~mm}$ to keep the thickness of the capillary fringe very small. A small container filled with $p$. putida and mineral oil was located at the position of the water table. The water table was maintained constant during the duration of the experiment thanks to a siphoning system. Self-potential was measured with $\mathrm{Ag} / \mathrm{AgCl}$ electrodes (the reference electrode was positioned at the top surface of the tank). The data reported in Figure 11 show clearly a dipolar anomaly located at the water table 9 days after inoculation of a sandbox with $p$. putida and mineral oil.

\section{Potential Mechanisms Facilitating Electron Transfer}

\subsection{Microbial Fuel Cells}

[49] We review first the basic concept of a bioelectrochemical system in which bacteria need to establish a link with a metallic electron donor or acceptor. In a microbial fuel cell, bacteria oxidize an electron donor and use an anodic electrode as the electron acceptor. The electrons flow from the metallic anode through the electrical circuit toward a terminal redox electron acceptor like oxygen at the metallic cathode. They can also be consumed at the cathode by other bacteria with the reduction of electrochemically positive electrons acceptors such as nitrate or metals [Thrash et al., 2007]. Cations in turn make up the charge balance by migrating from the anode to the cathode by electrodiffusion through a charge-selective membrane. Bacterial extracellular electron transfer mechanisms or shuttles are required whenever an electron acceptor or donor cannot enter the cells of the bacteria.

[50] A fundamental point to consider in a biogeobattery model is the role of bacteria as catalysts favoring electron transfer between electron donors (e.g., the organic matter) and the anode and symmetrically between the cathode and terminal electron acceptors. Catalysts are able to lower the activation energy between the electron donors and the anode and similarly between the cathode and electron acceptors. Their presence leads therefore to an ideal generator as described in sections 3 and 4. As such, the presence of bacteria improves the electrochemical properties of the electrodes in a microbial fuel cell. An ideal battery can then be reached for which the activation energy of the transfer of the electrons between the electron donors and the electronic conductor has been minimized according to the model described in section 3 .

[51] An outstanding question is to understand the mechanism of electron transfer in these systems. This remains a subject of ongoing research and debate. For Geobacter sulfurreducens, an anaerobic bacterium, the reduction of Fe(III) oxides may require pili [e.g., Reguera et al., 2005]. Shewanella oneidensis MR-1 also produces pili [Gorby et al., 2006] (Figure 12). These pili reach $50 \mathrm{~nm}$ in diameter and can extend several micrometers away from the cells (20 $\mu \mathrm{m}$ in the case of Geobacter sulfurreducens). Pili (and 

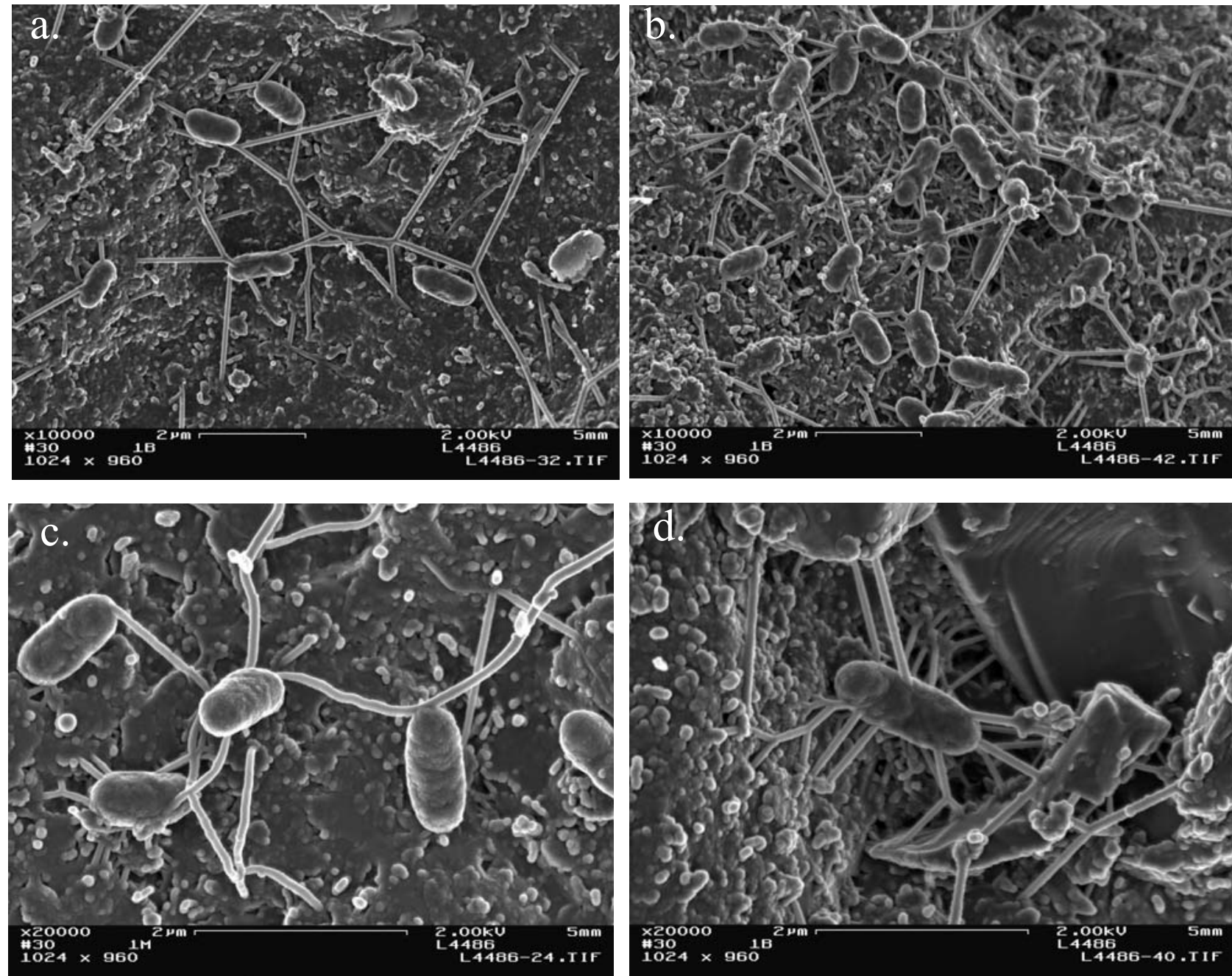

Figure 12. Shewanella oneidensis with pili showing the complexity of the 3-D organization of pili. $(\mathrm{a}-\mathrm{c})$ Illustration of how pili can be interconnected. (d) Illustration that several pili can start from a given bacteria (images are provided by Y. Gorby and were acquired in association with the Ntarlagiannis et al. [2007] study using a Field Emission Electron Microscope. See the methods section of the Ntarlagiannis et al. [2007] study for details).

the formation of biofilms) are specifically produced during the growth of the colonies on ferric oxides under conditions where the bacteria have problems finding terminal electron acceptors [see Childers et al., 2002; Reguera et al., 2005]. These pili seem to be highly conductive elements of the cell system and this is why they are called nanowires by Reguera et al. [2005] and Gorby et al. [2006] but the value of the conductivity is poorly constrained (likely in the range 10 to $100 \mathrm{~S} \mathrm{~m}^{-1}$ estimated from the data presented by Reguera et al. [2005]). Bacterial cells containing deletion mutations in the pilD gene do not produce such type of viable pili and no strong self-potential signals is observed in this case [Gorby et al., 2006].

[52] Holmes et al. [2006] pointed out the role of the c-type cytochrome $\mathrm{OmcS}$ in fuel cells to produce electrical currents implying that cytochrome c of Geobacter could be a key element acting as an electrical contact between the cells and the electrodes. A number of works have been performed recently, aimed at understanding how hemes (especially Heme I) and their linkers may form nanowires that are part of the electron transfer chain of the bacteria [Londer et al., 2006; Clarke et al., 2007].

[53] Geobacter can form thick $(>50 \mu \mathrm{m})$ biofilms on the surface of electrodes [Reguera et al., 2006]. Bacteria located at the external boundary of these biofilms have similar viability to those located closely to the electrodes. This suggests that pili may have an essential role as electron transfer mechanism through the whole biofilm. However, electronic conduction through these nanowires has yet to be directly confirmed.

\subsection{Possible Mechanisms Associated With Contaminant Plumes}

[54] We transfer now the concept of microbial fuel cell to the case described above for the contaminant plume of Entressen. Most of the cells of the bacteria would be located at the position of the water table, or right above it, where they have access to both nutrients and terminal electron acceptors (Figure 8c). This is also the place where, in a contaminant plume, the drop of the redox potential is the 


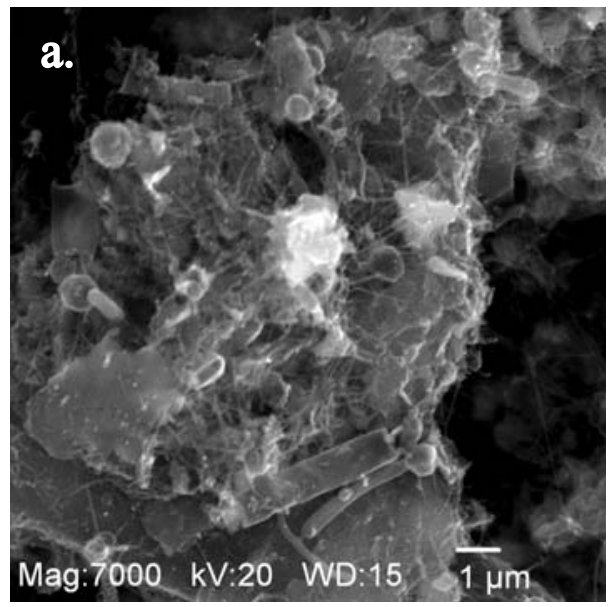

\section{c. Electrical conductivity profile}
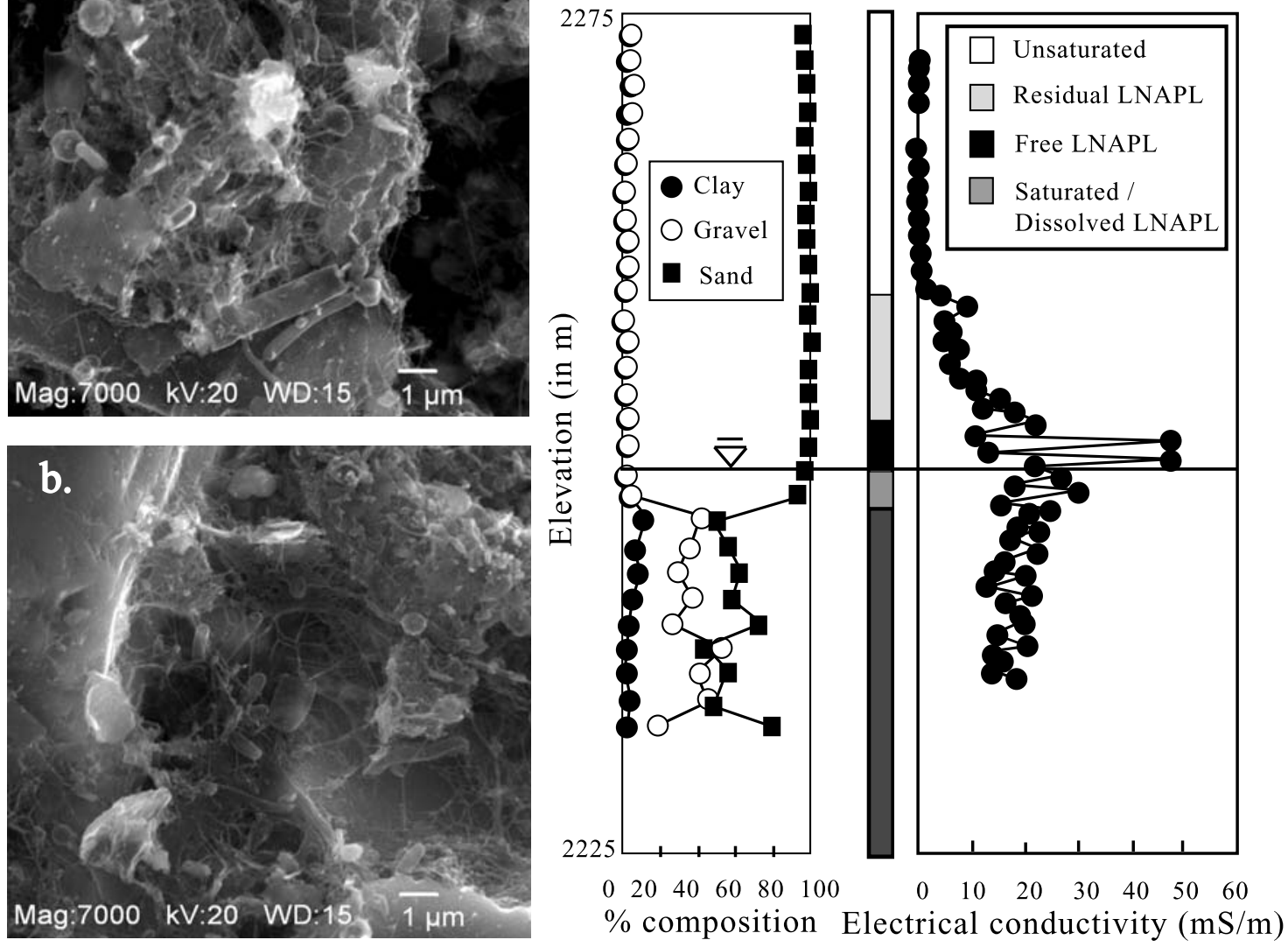

Figure 13. (a, b) SEM pictures showing a dense network of bacteria with "pili-like" structures in the capillary fringe at the hydrocarbon contaminated site of Carson City. We do not know if these pili are nanowires or not (E. Atekwana, unpublished work, 2009). Images were acquired using a JEOL JXM 6400 Scanning Electron Microscope System with an Evex EDS X-ray microanalysis system. (c) Soil lithology, soil conditions, and conductivity profiles of the petroleum-contaminated site. (left) Percentages of silt and clay, sand, and gravel. The inverted triangle denotes the level of the groundwater table. (middle) Residual, free, and dissolved LNAPL phases. (right) Levels of conductivity expressed in millisiemens per meter (modified from Atekwana et al. [2004]).

sharpest (see Arora et al. [2007] and Figure 8b). This suggests that the water table is an ideal position, for a contaminant plume (like the field of Entressen) to have an operating biogeobattery. Because the source body (where the source current density is nonnull) could be very thin, its resistance could be very small and therefore it would only present a small conductive anomaly in the field. This is in agreement with the observations made by Werkema et al. [2003] and Atekwana et al. [2004]. The capillary fringe is therefore the most active biological domain of the entire contaminant plume in a shallow unconfined aquifer like the one sketched in Figure 8. As shown by E. Atekwana (unpublished data, 2009), the fringes of contaminant plumes can have a high density of bacteria with possible pili (Figures 13a and 13b) that may explain the anomalously high conductivity of the capillary fringe with respect to the aquifer itself (Figure 13c) by proving an additional conduction pathway.

[55] We should also caution that the previous "transfer of concept" between microbial fuel cell and natural biogeobatteries occurs at different scales. Indeed, the scale at which nanowires mediate charge transfer in microbial fuel cells is on the order of micrometers (say $50 \mu \mathrm{m}$ on the surface of a fuel cell anode), whereas on a contaminant plume, redox gradients occur on a larger scale (millimeters to meters).

[56] We posit that there are two models that can describe electron transfer mechanisms associated with a contaminant plume. The first model (named model I, see Figure 14a) corresponds to the case where we have all the ingredients of a microbial fuel cell including the precipitation of minerals with electronic conduction at this position of the water table and the presence of diverse types of microcolonies below and above these minerals. Electron donors to bacteria can include organic matter and Fe-oxides and Fe-bearing phyllosilicates minerals can play the role of electron acceptors for organic matter oxidation. Geobacter can transfer the excess of electrons outside its cell onto iron minerals (conductors and semiconductors) through conductive pili. The contact between the pili and the electronic conductor or semiconductor is made through the Heme I of the terminal cytochrome and its efficiency depends on the distance 


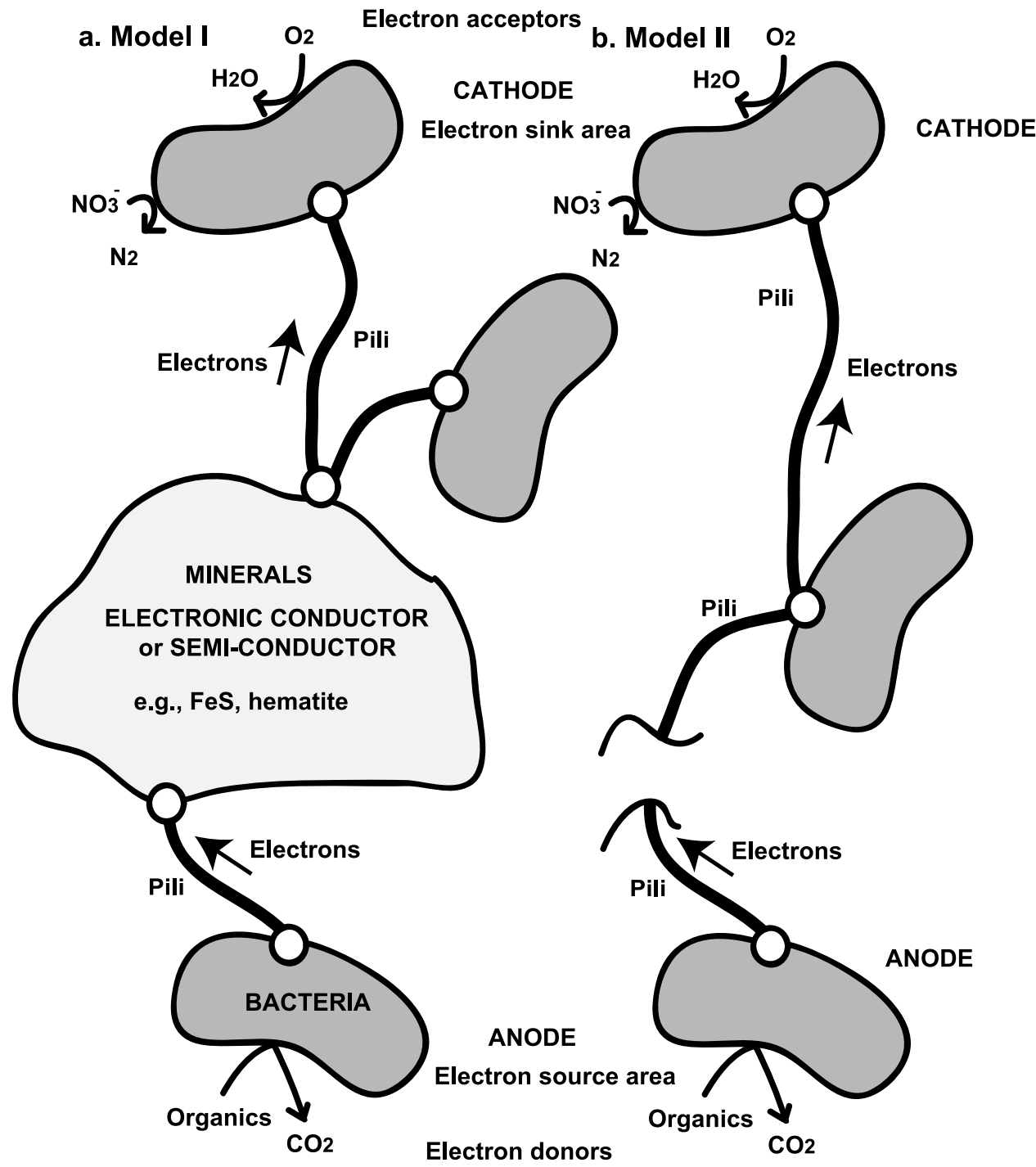

Figure 14. Sketch of two possible electron transfer mechanisms in a contaminant plume. (a) In model I, the presence of minerals facilitates electronic conduction. (b) In model II, only bacteria populations are connected by conductive pili. At the "bacterial anode," electrons are gained through the oxidation of the organic matter, iron oxides, or Fe-bearing phyllosilicates. The electrons are conveyed to the "bacterial cathode" through a network of conductive pili. At the "bacterial cathode," the reduction of oxygen and the nitrate prevails as electron acceptors. In this system, bacteria act as catalysts. The transport of electrons through the anode to the cathode of the microbattery may involve different bacterial communities and different electron transfer mechanisms including external electron shuttles.

(typically $1 \mathrm{~nm}$ ) between the iron of the heme to the iron of the conductive mineral. In this case, we will end up with a type of geobattery relatively similar to the one exhibited by ore bodies and especially by the "active electrode model" pathway. Indeed, the "passive electrode model" pathway would imply that an electronic conductor is present in the contaminant plume and that redox active species (e.g., $\mathrm{Fe}^{2+}$, $\mathrm{HS}^{-}$, etc.) generated during metabolism of organic contaminants would react with the conductor resulting in electron transfer. However, this mechanism would generate a nonlinear battery for which we see no proof in our field observations (see the Entressen case study). It should be noted however that a number of studies exist showing extremely rapid kinetics for $\mathrm{Fe}(\mathrm{II}) / \mathrm{Fe}(\mathrm{III})$ exchange reactions at the iron oxide-water interface and at the surface of clay minerals [Kozerski et al., 1997; Williams and Scherer, 2004; Gehin et al., 2007]. As such, microbes would not necessarily be needed to decrease the activation energy required between the electron donors and acceptors and the minerals with electronic conduction due to the fact that purely abiotic charge transfer processes involving $\mathrm{Fe}(\mathrm{II}) /$ Fe(III) couples is already extremely rapid. The microbes, however, are critical in that they replenish the source of oxidants (Fe(III)) and reductants (Fe(II)) needed for model I to remain operative over long timescales.

[57] The second model (model II, Figure 14b) is directly related to the following question: do we really need the precipitation of minerals with the ability to transfer electrons to have viable geobatteries in contaminant plumes? In other words, can different bacterial populations be in 
contact through pili and use this connection to exchange electrons in a contaminant plume or through the capillary fringe for example? New forms of bacterial interactions have been discovered recently demonstrating how multiple populations within microbial communities can cooperate to achieve energy generation [Aelterman et al., 2006; Milliken and May, 2007]. This question is still open at this stage. Rabaey et al. [2007] discussed the case of microbial communities with interaction in microbial fuel cell. They state that in this case, biofilms performing extracellular electron transfer are almost always present and can reach considerable thicknesses (hundreds of micrometers). It seems that bacteria in these biofilms develop a plurality of electron transfer strategies to overcome diffusion and activation energy limitations [Reguera et al., 2006]. Aelterman et al. [2006] showed an experiment in which the microbial community was dominated by a gram-positive bacterium at the point of maximal electrical power. However, this grampositive bacterium was unable to produce current when cultivated alone. This may indicate that microbial interactions may be a key to generate efficient bioelectrochemical biofilms, which suggests an exciting future avenue for exploration.

[58] These models raise also the intriguing possibility that conductive pili and minerals could work together to promote charge transfer, with the pili providing micrometerscale electrical bridging between conductive minerals that would otherwise not necessarily be in electrical contact with one another. In both cases, the anode of microbial fuel cell normally must operate at near neutral $\mathrm{pH}$ in the presence of various ionic species required for the function of the bacteria as biological catalysts. The presence of a large $\mathrm{pH}$ gradient between the anode and the cathode can strongly decrease the voltage efficiency of a microbial fuel cell [Torres et al., 2008]. In the case of the landfill of Entressen, the presence of carbonate rocks provide a natural buffer maintaining the $\mathrm{pH}$ of the pore water to a constant value $>7$. This prevents the formation of a large $\mathrm{pH}$ gradient between the cathode and the anode of the geobattery and therefore promotes its efficiency. This is may not always be the case, and future works will need to investigate the effect of the $\mathrm{pH}$ on the efficiency of biogeobatteries in natural systems in addition to the viability of bacterial community.

[59] Finally, regarding the range of electron transfer through pili, can we expect that the scale of electron transfer in subsurface systems may be larger than that observed in microbial fuels cells, where growth conditions are often optimal? The often-cited presence of "microsites" suggests that pilin-enabled electron transfer may occur over micronscale lengths in most natural environments. Indeed a vast collection of discrete, microscopic $(1-5 \mu \mathrm{m})$ "discharging batteries" accompanying microbe-catalyzed oxidationreduction processes may be sufficient to generate the reported self-potential anomalies. This means that each microbattery would work, at the microscopic scale, like the ore body shown in Figure 2a. The proposed model can capture the aggregate effect of millions of small dipoles exactly like millions of neurons in an active part of the brain can create a macroscopic dipole. Such a macroscopic dipole can be recorded by electroencephalography, an analog to self-potential signals at the surface of the scalp. In the brain, the electrical current is produced through the microscopic local exchange of ionic species at the synapses between these neurons [Kirschstein and Koehling, 2009]. A network of microbial fuel cells in series could provide a long-range transfer of a small current density and a network of microbial fuel cells in parallel a short-range transfer of a higher current density. A network in parallel can certainly be applied to the landfill of Entressen. More generically, it can be applied to charge transfer across interfaces with a redox jump (not necessarily the water table). Such a hypothesis could help to explain the existence of significant self-potential anomalies over disseminated sulfide mineralization.

\section{Concluding Statements}

[60] We developed a simple linear framework to describe abiotic processes and self-potential responses associated with geobatteries. Then, we extended the model to include biotic processes associated with contaminant plumes, and evaluated this model in light of different laboratory and field-based studies. We came to the conclusion that without an electronic conductor, self-potential anomalies over plumes are quite small (less than 20 millivolts) in agreement with experimental works. When an electronic conductor is present, the self-potential magnitudes are in hundreds of millivolts and are directly a signature of the redox potential distribution in the aquifer. Although the nature of the conductor and associated mechanisms within the model remains unknown, possible explanations include (1) the presence of conductive pili between bacteria at the water table, (2) the precipitation of electronically conductive particles at the water table with the potential role of iron oxides and iron-bearing phyllosilicates, or (3) a combination of both processes. The study represents an advance in linking geophysical and microbiological concepts within a biogeobattery model that may ultimately provide a fully mechanistic explanation of self-potential responses associated with contaminated subsurface environments and a nonintrusive or minimally invasive way to monitor redox reactions.

\section{Appendix A: Multipole Expansion of the Self-Potential Field}

[61] We can use a multipole expansion of the electrostatic potential to look at the electrical field in the far field of a geobattery. We first consider an infinite homogenous conductive material in 3-D. The only heterogeneity in the electrical conductivity distribution occurs through the interface $\partial \Omega$ (the surface of the ore body in Figure 2a). We consider situations where the observation stations (where the self-potential signals are measured) are far enough from the source to treat the source as a point source (this is the case of a deep ore body for instance). The multipole expansion of the electrical potential represents the expansion of the electrical potential distribution in successive power of (1/r) [e.g., Griffiths, 1999, chapter 3],

$$
\psi(\mathbf{r})=\frac{1}{4 \pi \varepsilon_{0}} \sum_{n=0}^{\infty}(1 / r)^{n+1} \int_{\Omega}\left(r^{\prime}\right)^{n} P_{n}\left(\cos \theta^{\prime}\right) \rho_{e}\left(\mathbf{r}^{\prime}\right) d V^{\prime},
$$


where $P_{n}(x)$ are Legendre polynomials. In the following, we note this expansion as,

$$
\psi(\mathbf{r})=\psi^{0}(\mathbf{r})+\psi^{1}(\mathbf{r})+\psi^{2}(\mathbf{r})+\ldots
$$

where $\psi^{0}(\mathbf{r})$ represents the monopole term, $\psi^{1}(\mathbf{r})$ the dipole term, $\psi^{2}(\mathbf{r})$ the quadrupole term, and so on. If $r$ is large, the expansion is dominated by the first term,

$$
\begin{gathered}
\psi^{0}(\mathbf{r})=\frac{1}{4 \pi \varepsilon_{0}}(1 / r) \int_{\Omega} \rho_{e}\left(\mathbf{r}^{\prime}\right) d V^{\prime} \\
\psi^{0}(\mathbf{r})=\frac{1}{4 \pi \varepsilon_{0}} \frac{Q}{r}
\end{gathered}
$$

where the total charge $Q$ corresponds to the moment of order 1 of the charge distribution $\rho_{e}\left(\mathbf{r}^{\prime}\right)$,

$$
\begin{gathered}
Q=\int_{\Omega} \rho_{e}\left(\mathbf{r}^{\prime}\right) d V^{\prime} \\
Q=-\int_{\Omega}\left(\frac{\nabla \cdot \mathbf{j}_{S}}{\sigma}-\nabla \ln \sigma \cdot \mathbf{E}\right) d V^{\prime} .
\end{gathered}
$$

We focus from now on the primary source term (the first term in the right hand side of equation A6) and we neglect the secondary source term associated with the jump in electrical conductivity through $\partial \Omega$. With this assumption using equation (A6) and the divergence theorem, we obtain,

$$
Q=-\frac{1}{\sigma} \oint_{\partial \Omega} \mathbf{j}_{S} \cdot \mathrm{d} \mathbf{a},
$$

where da is the surface element of the interface $\partial \Omega$ pointing outward from the ore body. The charge conservation equation yields:

$$
\oint_{\partial \Omega} \mathbf{j}_{S} \cdot \mathrm{d} \mathbf{a}=0
$$

which indicates that the total flux of electrical charges through $\partial \Omega$ is equal to zero (i.e., there is no charge storage inside the ore body). Therefore, the monopole term of the multipole expansion series is equal to zero. It follows that the leading term is the dipolar term given by,

$$
\psi^{1}(\mathbf{r})=\frac{1}{4 \pi \varepsilon_{0}} \frac{1}{r^{2}} \int_{\Omega} r^{\prime} \cos \theta^{\prime} \rho_{e}\left(\mathbf{r}^{\prime}\right) d V^{\prime} .
$$

If we note $\hat{\mathbf{r}}$ the unit vector between the origin of the Cartesian coordinate system and an observation point $\mathrm{P}$, we have $\hat{\mathbf{r}} \cdot \mathbf{r}^{\prime}=\mathbf{r}^{\prime} \cos \theta^{\prime}$. This yields:

$$
\psi^{1}(\mathbf{r})=\frac{1}{4 \pi \varepsilon_{0}} \frac{1}{r^{2}} \hat{\mathbf{r}} \cdot \int_{\Omega} \mathbf{r}^{\prime} \rho_{e}\left(\mathbf{r}^{\prime}\right) d V^{\prime} .
$$

The dipole moment in the second-order moment of the charge distribution is,

$$
\mathbf{p}=\int_{\Omega} \mathbf{r}^{\prime} \rho_{e}\left(\mathbf{r}^{\prime}\right) d V^{\prime}
$$

Therefore,

$$
\psi^{1}(\mathbf{r})=\frac{1}{4 \pi \varepsilon_{0}} \frac{1}{r^{2}} \hat{\mathbf{r}} \cdot \mathbf{p}
$$

[62] We have therefore demonstrated that the electrical field created in the ground by an ore body is dominated by the dipolar field in the far field.

[63] Acknowledgments. This research was supported by the Office of Science (BER), U.S. Department of Energy, grants DE-AC0205CH11231, DE-FG02-08ER646559, and DE-FG02-07ER64413, and a CAM Scholarship to C. A. Mendonça from the Brazilian Research Council $\mathrm{CNPq}$ 482381/2007-8. We thank E. E. Roden and Y. Gorby for fruitful discussions. We want to express our deep gratitude to three exceptional referees who provided very useful comments to our manuscript.

\section{References}

Aelterman, P., K. Rabaey, H. T. Pham, N. Boon, and W. Verstraete (2006), Continuous electricity generation at high voltages and currents using stacked microbial fuel cells, Environ. Sci. Technol., 40, 3388-3394, doi:10.1021/es0525511.

Arora, T., A. Revil, N. Linde, and J. Castermant (2007), Non-intrusive determination of the redox potential of contaminant plumes using the self-potential method, Contam. Hydrol., 92, 274-292, doi:10.1016/ j.jconhyd.2007.01.018.

Ashworth, D. J., and G. Shaw (2006), A comparison of the soil migration and plan uptake of radioactive chlorine and iodine from contaminated groundwater, J. Environ. Radioact., 89, 61-80, doi:10.1016/j.jenvrad. 2006.03.006.

Atekwana, E. A., E. A. Atekwana, D. D. Werkema, J. P. Allen, L. A. Smart, J. W. Duris, D. P. Cassidy, W. A. Sauck, and S. Rossbach (2004), Evidence for microbial enhanced electrical conductivity in hydrocarboncontaminated sediments, Geophys. Res. Lett., 31, L23501, doi:10.1029/ 2004GL021359.

Biesheuvel, P. M., A. A. Franco, and M. Z. Bazant (2009), Diffuse charge effects in fuel cell membranes, J. Electrochem. Soc., 156(2), B225B233, doi:10.1149/1.3021035.

Bigalke, J., and E. W. Grabner (1997), The Geobattery model: A contribution to large scale electrochemistry, Electrochim. Acta, 42, 3443-3452, doi:10.1016/S0013-4686(97)00053-4.

Blakely, R. J. (1995), Potential Theory in Gravity and Magnetic Applications, Cambridge Univ. Press, New York.

Bockris, J., O. M. Bockris, and A. K. N. Reddy (1970), Modern Electrochemistry, vol. 2, 1432 pp., Plenum, New York.

Castermant, J., C. A. Mendonça, A. Revil, F. Trolard, G. Bourrié, and N. Linde (2008), Redox potential distribution inferred from self-potential measurements during the corrosion of a burden metallic body, Geophys. Prospect., 56, 269-282, doi:10.1111/j.1365-2478.2007.00675.x.

Childers, S. E., S. Ciufo, and D. R. Lovley (2002), Geobacter metallireducens accesses insoluble Fe(III) oxide by chemotaxis, Nature, 416, 767769, doi:10.1038/416767a.

Christensen, T. H., P. L. Bjerg, S. A. Banwart, R. Jakobsen, G. Heron, and H.-J. Albrechtsen (2000), Characterization of redox conditions in groundwater contaminant plumes, J. Contam. Hydrol., 45, 165-241, doi:10.1016/S0169-7722(00)00109-1.

Clarke, T. A., J. A. Cole, D. J. Richardson, and A. M. Hemmings (2007), The crystal structure of the pentahaem c-type cytochrome NrfB and characterization of its solution-state interaction with the pentahaem nitrite reductase NrfA, Biochem. J., 406, 19-30, doi:10.1042/BJ20070321.

Corwin, R. F. (1997), The self-potential method for environmental and engineering applications: Geotechnical and environmental geophysics, in Investigations in Geophysics, vol. 1, edited by S. H. Ward, Soc. of Explor. Geophys., Tulsa, Okla.

Crespy, A., A. Revil, N. Linde, S. Byrdina, A. Jardani, A. Bolève, and P. Henry (2008), Detection and localization of hydromechanical disturbances in a sandbox using the self-potential method, J. Geophys. Res., 113, B01205, doi:10.1029/2007JB005042. 
Davis, C., et al. (2006), Self-potential signatures associated with the in-situ biogeochemical processes of a biological permeable reactive barrier, Portadown, Northern Ireland, paper presented at Annual Meeting and Exposition, Geol. Soc. of Am., Philadelphia, Pa.

Doherty, R. D. (2002), Modelling a permeable reactive barrier (PRB) in a manufactured gas plant site, Portadown, Northern Ireland, Ph.D. thesis, 261 pp., Queen's Univ. Belfast, Belfast, U. K.

Doherty, R. D., D. H. Phillips, K. L. McGeough, K. P. Walsh, and R. M Kalin (2006), Development of a modified fly ash as a permeable reactive barrier media for a former manufactured gas plant site Northern Ireland, Environ. Geol., 50, 37-46, doi:10.1007/s00254-005-0170-4.

Ferguson, A. S., R. D. Doherty, M. J. Larkin, R. M. Kalin, V. Irvine, and U. S. Öfterdinger (2003), Toxicity assessment of a former manufactured gas plant, Bull. Environ. Contam. Toxicol., 71, 21-30, doi:10.1007/ s00128-003-0125-y.

Gehin, A., J. M. Greneche, C. Tournassat, J. Brendle, D. G. Rancourt, and L. Charlet (2007), Reversible surface-sorption-induced electron-transfer oxidation of $\mathrm{Fe}(\mathrm{II})$ at reactive sites on a synthetic clay mineral, Geochim. Cosmochim. Acta, 71(4), 863-876, doi:10.1016/j.gca.2006.10.019.

Gorby, Y. A., et al. (2006), Electrically conductive bacterial nanowires produced by Shewanella oneidensis strain MR-1 and other microorganisms, Proc. Natl. Acad. Sci. U. S. A., 103, 11,358-11,363, doi:10.1073/ pnas.0604517103.

Greenhouse, J. P., and R. D. Harris (1983), Migration of contaminants in groundwater at a landfill: A case study: 7. DC, VLF, and inductive resistivity surveys, J. Hydrol., 63, 177-197, doi:10.1016/0022-1694(83) 90227-5.

Griffiths, D. J. (1999), Introduction to Electrodynamics, 3rd ed., 576 pp., Prentice-Hall, London.

Hämmann, M., H. R. Maurer, A. G. Green, and H. Horstmeyer (1997), Selfpotential image reconstruction: Capabilities and limitations, J. Environ. Eng. Geophys., 2, 21-35, doi:10.4133/JEEG2.1.21.

Holmes, D. E., et al. (2006), Microarray and genetic analysis of electron transfer to electrodes in Geobacter sulfurreducens, Environ. Microbiol., 8, 1805-1815, doi:10.1111/j.1462-2920.2006.01065.x.

Holstetler, J. D. (1984), Electrode electrons, aqueous electrons, and redox potentials in natural waters, Am. J. Sci., 284, 734-759.

Jakobsen, R. (2007), Redox microniches in groundwater: A model study on the geometric and kinetic conditions required for concomitant Fe oxide reduction, sulfate reduction, and methanogenesis, Water Resour. Res., 43, W12S12, doi:10.1029/2006WR005663.

Jakobsen, R., and D. Postma (1999), Redox zoning rates of sulfate reduction and interactions with Fe-reduction and methanogenesis in a shallow sandy aquifer, Romo, Denmark, Geochim. Cosmochim. Acta, 63, 137151, doi:10.1016/S0016-7037(98)00272-5.

Kelley, D. L., K. D. Kelley, W. B. Coker, B. Caughlin, and M. E. Doherty (2006), Beyond the obvious limits of ore bodies: The use of mineralogical, geochemical, and biological features for the remote detection of mineralization, Econ. Geol., 101(4), 729-752, doi:10.2113/gsecongeo.101. 4.729 .

Kirschstein, T., and R. Koehling (2009), What is the source of the EEG? Clin. EEG Neurosci., 40(3), 146-149.

Kozerski, G. E., M. A. Fiorentino, and M. E. Ketterer (1997), Determination of aqueous Fe III/II electron self-exchange rates using enriched stable isotope labels, ion chromatography, and inductively coupled plasma mass spectrometry, Anal. Chem., 69(4), 783-788, doi:10.1021/ ac960838y.

Kulessa, B., R. Kalin, R. Doherty, and D. Chandler (2006), Self-potential (SP) and active electrical geophysical assessment of bioremediation at a contaminated gasworks plant, Eos Trans. $A G U, 87(36)$, Jt. Assem. Suppl., Abstract NS34A-04.

Linde, N., and A. Revil (2007), Inverting residual self-potential data for redox potentials of contaminant plumes, Geophys. Res. Lett., 34, L14302, doi:10.1029/2007GL030084.

Logan, B., et al. (2006), Microbial fuel cells: Methodology and technology, Environ. Sci. Technol., 39, 4317-4320.

Londer, Y. Y., P. R. Pokkuluri, V. Orshonsky, L. Orchonsky, and M. Shiffer (2006), Heterologous expression of dodecaheme "nanowire" cytochrome c from Geobacter sulfurreducens, Protein Expr. Purif., 47, 241-248, doi:10.1016/j.pep.2005.11.017.

Maineult, A., Y. Bernabé, and P. Ackerer (2006), Detection of advected, reacting redox fronts from self-potential measurements, J. Contam. Hydrol., 86, 32-52, doi:10.1016/j.jconhyd.2006.02.007.

Mendonça, C. A. (2008), Forward and Inverse self-potential modeling in mineral exploration, Geophysics, 73(1), F33-F43, doi:10.1190/ 1.2821191.

Milliken, C. E., and H. D. May (2007), Sustained generation of electricity by the spore-forming, Gram-positive, Desulfitobacterium hafniense strain DCB2, Appl. Microbiol. Biotechnol., 73, 1180-1189, doi:10.1007/ s00253-006-0564-6.
Minsley, B. J., J. Sogade, and F. D. Morgan (2007), Three-dimensional selfpotential inversion for subsurface DNAPL contaminant detection at the Savannah River Site, South Carolina, Water Resour. Res., 43, W04429, doi:10.1029/2005WR003996.

Naudet, V., and A. Revil (2005), A sandbox experiment to investigate bacteria-mediated redox processes on self-potential signals, Geophys. Res. Lett., 32, L11405, doi:10.1029/2005GL022735.

Naudet, V., A. Revil, J.-Y. Bottero, and P. Bégassat (2003), Relationship between self-potential (SP) signals and redox conditions in contaminated groundwater, Geophys. Res. Lett., 30(21), 2091, doi:10.1029/ 2003GL018096.

Naudet, V., A. Revil, E. Rizzo, J. Y. Bottero, and P. Bégassat (2004), Ground water redox conditions and conductivity in a contaminant plume from geoelectrical investigations, Hydrol. Earth Syst. Sci., 8(1), 8-22.

Nordstrom, D. K. (2000), Aqueous redox chemistry and the behavior of iron in acid mine waters, in Proceedings of the Workshop on Monitoring Oxidation-Reduction Processes for Ground Water Restoration, Dallas, Texas, April 25-27, 2000, Cincinnati, OH, edited by R. T. Wilkin, R. D. Ludwig, and R. G. Ford, EPA/600/R-02/002, pp. 43-47, U.S. Environ. Prot. Agency, Washington, D. C.

Ntarlagiannis, D., E. A. Atekwana, E. A. Hill, and Y. Gorby (2007), Microbial nanowires: Is the subsurface "hardwired"?, Geophys. Res. Lett., 34, L17305, doi:10.1029/2007GL030426.

Petiau, G. (2000), Second generation of lead-lead chloride electrodes for geophysical applications, Pure Appl. Geophys., 157, 357-382, doi: $10.1007 / \mathrm{s} 000240050004$.

Postma, D., and R. Jakobsen (1996), Redox zonation: Equilibrium constraints on the Fe (III)/SO4-reduction interface, Geochim. Cosmochim. Acta, 60, 3169-3175, doi:10.1016/0016-7037(96)00156-1.

Rabaey, K., J. Rodriguz, L. L. Blackall, J. Keller, P. Gross, D. Batstone, W. Verstraete, and K. H. Nealson (2007), Microbial ecology meets electrochemistry: Electricity-driven and driving communities, ISME J., 1 9-18, doi:10.1038/ismej.2007.4.

Reguera, G., K. D. McCarthy, T. Metha, J. S. Nicol, M. T. Tuominen, and D. R. Lovley (2005), Extracellular electron transfer via microbial nanowires, Nature, 435, 1098-1101, doi:10.1038/nature03661.

Reguera, G., K. P. Kevin, J. S. Nicoll, S. F. Covalla, T. L. Wooddard, and D. R. Lovley (2006), Biofilm and nanowire production leads to increased current in Geobacter sulfurreducens fuel cells, Appl. Environ. Microbiol., 72, 7345-7348, doi:10.1128/AEM.01444-06.

Revil, A. (1999), Ionic diffusivity, electrical conductivity, membrane and thermoelectric potentials in colloids and granular porous media: A unified model, J. Colloid Interface Sci., 212, 503-522, doi:10.1006/jcis.1998. 6077

Revil, A., and N. Linde (2006), Chemico-electromechanical coupling in microporous media, J. Colloid Interface Sci., 302, 682-694, doi:10.1016/j.jcis.2006.06.051

Revil, A., P. Leroy, and K. Titov (2005), Characterization of transport properties of argillaceous sediments: Application to the Callovo-Oxfordian Argillite, J. Geophys. Res., 110, B06202, doi:10.1029/2004JB003442.

Revil, A., F. Trolard, G. Bourrié, J. Castermant, A. Jardani, and C. A. Mendonça (2009), Ionic contribution to the self-potential signals associated with a redox front, J. Contam. Hydrol., 109, 27-39.

Rizzo, E., B. Suski, A. Revil, S. Straface, and S. Troisi (2004), Self-potential signals associated with pumping-tests experiments, J. Geophys. Res., 109, B10203, doi:10.1029/2004JB003049.

Sato, M., and H. M. Mooney (1960), The electrochemical mechanism of sulfide self-potentials, Geophysics, 25, 226-249, doi:10.1190/ 1.1438689.

Sill, W. R. (1983), Self-potential modeling from primary flows, Geophysics, 48, 76-86, doi:10.1190/1.1441409.

Sivenas, P., and F. W. Beales (1982), Natural geobatteries associated with sulphide ore deposits. I. Theoretical studies, J. Geochem. Explor, 17, 123-143, doi:10.1016/0375-6742(82)90029-2.

Stoll, J., J. Bigalke, and E. W. Grabner (1995), Electrochemical modeling of self-potential anomalies, Surv. Geophys., 16(1), 107-120, doi:10.1007/ BF00682715.

Swerhone, G. D. W., J. R. Lawrence, J. G. Richards, and M. J. Hendry (2007), Construction and testing of a durable platinum wire Eh electrode for in situ redox measurements in the subsurface, Ground Water Monit. Rem., 19(2), 132-136, doi:10.1111/j.1745-6592.1999.tb00214.x.

Thompson, K. F., J. Holt, and G. Kennedy (1997), Eh mapping locates petroleum seepage, Sea Technol., 38, 47-53.

Thorstenson, D. C. (1984), The concept of electron activity and its relation to redox potentials in aqueous geochemical systems, U.S. Geol. Surv. Open File Rep., 84-072, 45 pp.

Thrash, J. C., J. I. VanTrump, K. A. Weber, E. Miller, L. A. Achenbach, and J. D. Coates (2007), Electrochemical stimulation of microbial perchlorate reduction, Environ. Sci. Technol., 41, 1740-1746, doi:10.1021/ es062772m. 
Timm, F., and P. Möller (2001), The relation between electric and redox potential: Evidence from laboratory and field measurements, J. Geochem. Explor., 72, 115-128, doi:10.1016/S0375-6742(01)00157-1.

Torres, C. I., H. S. Lee, and B. E. Rittman (2008), Carbonate species as $\mathrm{OH}^{-}$carriers for decreasing the $\mathrm{pH}$ gradient between cathode and anode in biological fuel cells, Environ. Sci. Technol., 42(23), 8773-8777, doi:10.1021/es8019353.

Vichabian, Y., P. Reppert, and F. D. Morgan (1999), Self potential mapping of contaminants, paper presented at Symposium on the Application of Geophysics to Engineering and Environmental Problems, Environ. and Eng. Geophys. Soc., Oakland, Calif., 14-18 March.

Wadey, P., G. Shaw, and J. N. B. Bell (2001), Vadose zone processes and chemical transport, J. Environ. Qual., 30, 1341-1353.

Weigel, M. (1989), Self-potential surveys on waste dumps-Theory and practice in detection of subsurface flow phenomena, in Lecture Notes in Earth Sciences, vol. 27, pp. 109-120, Springer, Berlin.
Werkema, D. D., et al. (2003), Investigating the electrical response of hydrocarbon contamination undergoing biodegradation, Geophys. Res. Lett., 30(12), 1647, doi:10.1029/2003GL017346.

Williams, A. G. B., and M. M. Scherer (2004), Spectroscopic evidence for $\mathrm{Fe}(\mathrm{II})-\mathrm{Fe}$ (III) electron transfer at the iron oxide-water interface, Environ. Sci. Technol., 38(18), 4782-4790, doi:10.1021/es049373g.

E. A. Atekwana, Boone Pickens School of Geology, Oklahoma State University, Stillwater, OK 74078, USA. (estella.atekwana@okstate.edu)

K. J. Bohlen and A. Revil, Department of Geophysics, Colorado School of Mines, 1500 Illinois St., Golden, CO 80401, USA. (arevil@mines.edu)

S. S. Hubbard, Earth Science Division, Lawrence Berkeley National Laboratory, Berkeley, CA 94720, USA. (sshubbard@lbl.gov)

B. Kulessa, School of the Environment and Society, Swansea University, Swansea SA2 8PP, UK. (b.kulessa@swansea.ac.uk)

C. A. Mendonça, Geofísica e Ciências Atmosféricas, Instituto de Astronomia, Sao Paulo 05508-090, Brazil. (mendonca@iag.usp.br) 